\title{
Three-Point Bending Behaviour of a Fabricated Concrete Connection with Steel Plate Hoop and Bolts
}

\author{
Dawei Yuan $\mathbb{D D}^{1,2}$ Qingning Li, ${ }^{1}$ Jianpeng Sun $\mathbb{D D}^{1}{ }^{1}$ Jiaolei Zhang, ${ }^{1}$ and Weishan Jiang ${ }^{1}$ \\ ${ }^{1}$ School of Civil Engineering, Xi'an University of Architecture \& Technology, Xi'an 710055, China \\ ${ }^{2}$ School of Civil Engineering and Architecture, Xinxiang College, Xinxiang 453003, China \\ Correspondence should be addressed to Jianpeng Sun; sunjianpeng2001@163.com
}

Received 5 February 2021; Accepted 26 April 2021; Published 5 May 2021

Academic Editor: Francesco Colangelo

Copyright (c) 2021 Dawei Yuan et al. This is an open access article distributed under the Creative Commons Attribution License, which permits unrestricted use, distribution, and reproduction in any medium, provided the original work is properly cited.

As the development of building industrialization and housing industrialization is speeding up in China, the application of precast concrete structure has been the research focus. The connection of prefabricated components is one of the key technologies in prefabricated concrete structure. So, a new type of column-column connection with steel plate hoop and bolts is proposed in this paper to promote the application of precast concrete structure. In order to reveal the flexural behavior and force transfer mechanism about this new type connection, six precast concrete beams and one integral casting beam were tested by the threepoint bending under loading and unloading cycle. The comparative analysis is made between the new type connection and traditional integral cast-in-place member from the aspects of test phenomenon, failure mode, and load-deflection relationship. The analysis results show that the new type connection has the same bending bearing capacity as the integral casting member. Based on the analysis of the load-strain relationship of longitudinal reinforcement, bolts, and steel plate hoop, the moment transmission mechanism and theoretical calculation formula of the new type connection are proposed, and the theoretical calculation results are consistent with the experimental results.

\section{Introduction}

Building industrialization is speeding up in China in order to solve the increasingly prominent problems faced by the construction industry, such as environmental pollution, labor shortage, rising labor costs, and large amount of construction waste. However, the key factor limiting the popularization of precast concrete structures is the seismic performance of the joints. The failure of connections between precast concrete members in earthquake will lead to local failure and even the dispersion and collapse of the whole structure [1]. This view has been repeatedly proved in recent earthquakes, such as the 1994 Northridge earthquake in the United States, the 2010 Christchurch earthquakes in New Zealand, the 2011 Van earthquake in Turkey [2-4]. In order to develop the connection of precast concrete structure, China Academy of Building Sciences (CABR) carried out the national science and technology support project of "research and demonstration of new prefabricated concrete building technology" from 2011 to 2017 [5]. The main research results are as follows: tenon connection [6], groutinganchoring connection $[7,8]$, insertion connection [9], column-beam-plate stacking joint [10], and so on. Although these connection forms have good mechanical properties, they have some weakness, such as complex construction procedures and slow construction speed [11-13]. This paper presents a new type of column-to-column connection to improve this problem, as shown in Figure 1.

This new type connection effectively replaces the longitudinal bar connection in the construction site and improves the assembly speed. However, this connection mode has a unique way to transfer bending moment, which is different from the traditional connection mode and bending mechanism of concrete filled steel tube [14], and there are few related studies. Therefore, it is necessary to study the flexural performance of this kind connection. 


\section{Experimental Program}

2.1. Specimen Design. In this test, six new fabricated connection specimens (PRCB-01-PRCB-06) and one integral casting beam (RCB-00) were made. PRCB-01 and PRCB-02 were fixed by steel plate hoop with bolts, while PRCB03-PRCB-06 were connected by pure steel plate. The design dimensions of components and loading scheme are show in Figure 2. The material parameters of the specimens are shown in Table 1.

2.2. Specimen Preparation. The production process of test specimens is shown in Figure 3. The reinforcement skeleton adopts closed rectangular stirrup, and $90^{\circ}$ hook is adopted at the end of longitudinal reinforcement. The hook length of longitudinal reinforcement is $120 \mathrm{~mm}$. All the specimens were cast with commercial concrete, and the strength grade of commercial concrete is C30. Two groove steel plates are used to splice into rectangular cylinder, and Q235 steel plate is used as steel material.

2.3. Material Properties. The mechanical properties of longitudinal reinforcement, stirrup, bolts, and steel plates were tested according to metallic materials tensile testing [15]. The test results are shown in Table 2. According to test method of mechanical properties on ordinary concrete [16], the concrete compressive cube strength of beam is $33.8 \mathrm{MPa}$, and the axial compressive strength is $22.6 \mathrm{MPa}$. The concrete compressive cube strength of the filling grout is $43.2 \mathrm{MPa}$.

2.4. Test Setup and Loading History. In order to produce pure bending section, three-point bending test was adopted, as shown in Figure 4. The specimen beam was placed on the sliding bearings, and the vertical force exerted by $100 \mathrm{~T}$ hydraulic jack is evenly distributed to the three-point of the specimen through steel beam. Three loading-unloading cycles were carried out during the test, and the specimens would be loaded to failure at the end of cyclic loading. The estimated load of each stage is $20 \mathrm{kN}$, and its value is one third of the estimated bending capacity of the cast-in-place specimen beam (RCB-00). Loading history is shown in Figure 5.

2.5. Arrangement of Test Points. In order to acquaint the strain variation of the steel hoop during the test loading process, strain gauges are arranged on the top and bottom surfaces of the steel hoop, and the specific locations are shown in Figures 6(a) and 6(b). The strain gauge is placed at the No. 4, No. 5, and No. 6 positions of the longitudinal reinforcement at the bottom of the beam, which can obtain the strain regularity of the longitudinal reinforcement from the outside of the steel hoop to the inside of the steel hoop. In addition, the strain gauges are set at No. 7 and No. 8 positions at bolts in order to test the strain of the bolt bars, as shown in Figures 6(c) and 6(d). The displacement meter at No.1 position is used to measure the deflection of the specimen beam, and the displacement meters at No. 2 and

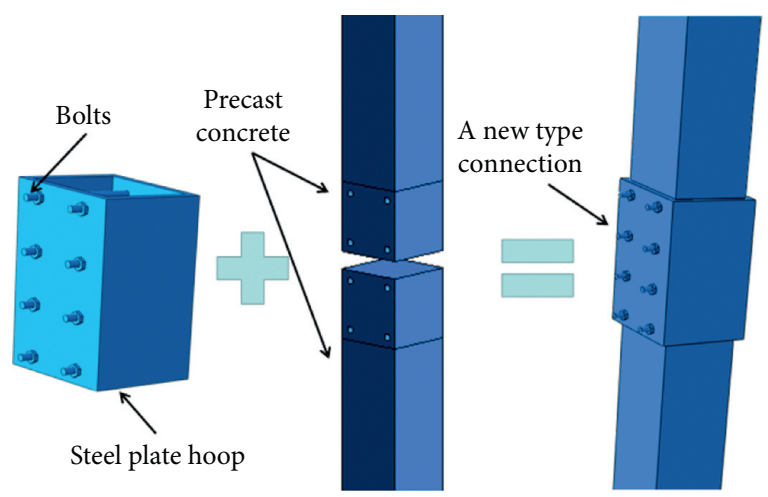

FIGURE 1: Steel tube with bolts connection.

No.3 positions are used to measure the slip between the steel hoop and the prefabricated member, and the specific positions are shown in Figure 2. All test data are collected by TDS602 data acquisition instrument.

\section{Analysis on Test Results}

3.1. Failure Modes of the Specimens. The failure modes of the seven specimen beams can be divided into three types. The first type of failure is the yielding of steel reinforcement followed by crushing of concrete at compression side of the beam; RCB-00, PRCB-01, PRCB-02, and PRCB-04 belong to this type. The second kind of failure is caused by excessive deformation; PRCB-03 and PRCB-06 belong to this type. The third kind of failure is the tearing failure of steel hoop, which occurs in PRCB-05. The failure phenomena of the seven test beams are shown in Figure 7.

3.1.1. The First Kind of Failure. When the loading value reaches about $14 \mathrm{kN}$, tiny cracks begin to appear in the reinforced concrete members. When the loading reaches $60 \mathrm{kN}$, the cracking speed is obviously accelerated, the deflection of the specimen is obvious, and some cracks develop to 0.75 of the height of the specimen. When the load reaches about $69 \mathrm{kN}$, the through cracks appear and the concrete on the upper part of the beam is crushed. During the loading process, no obvious relative slip was observed in the pure bending sections of PRCB-01, PRCB-02, and PRCB-04, and no crushing failure was found in the concrete inside the steel hoop.

3.1.2. The Second Kind of Failure. There is no crushing phenomenon in the compression concrete of PRCB-03 and PRCB-06. When PRCB-03 is loaded to $13 \mathrm{kN}$, tiny cracks appear outside the steel hoop. When the load reaches $20 \mathrm{kN}$, the steel plate hoop makes a noise inside. After loading to $55 \mathrm{kN}$, the deflection and relative slip of the beam increase obviously. At the beginning of loading, the PRCB-06 beam has obvious deformation. At about $10 \mathrm{kN}$, cracks begin to appear on the outside of steel hoop. After loading to $40 \mathrm{kN}$, the slip between the steel hoop and the precast concrete member appears abrupt recovery during the unloading process. When it was loaded to $50 \mathrm{kN}$ again, the bearing 

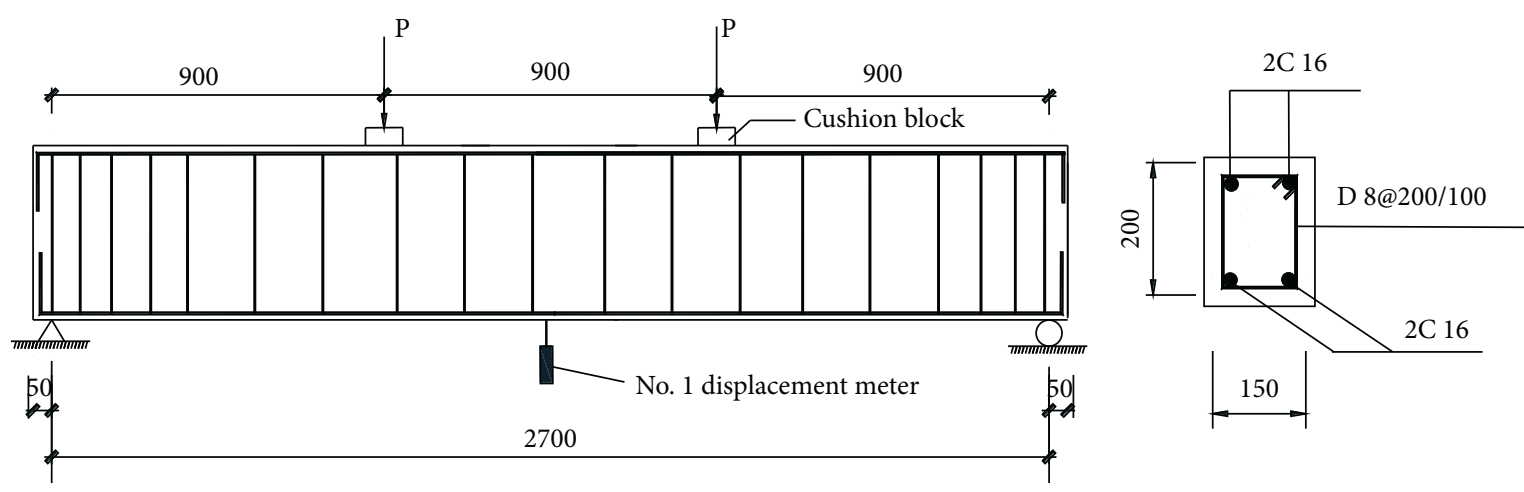

(a)

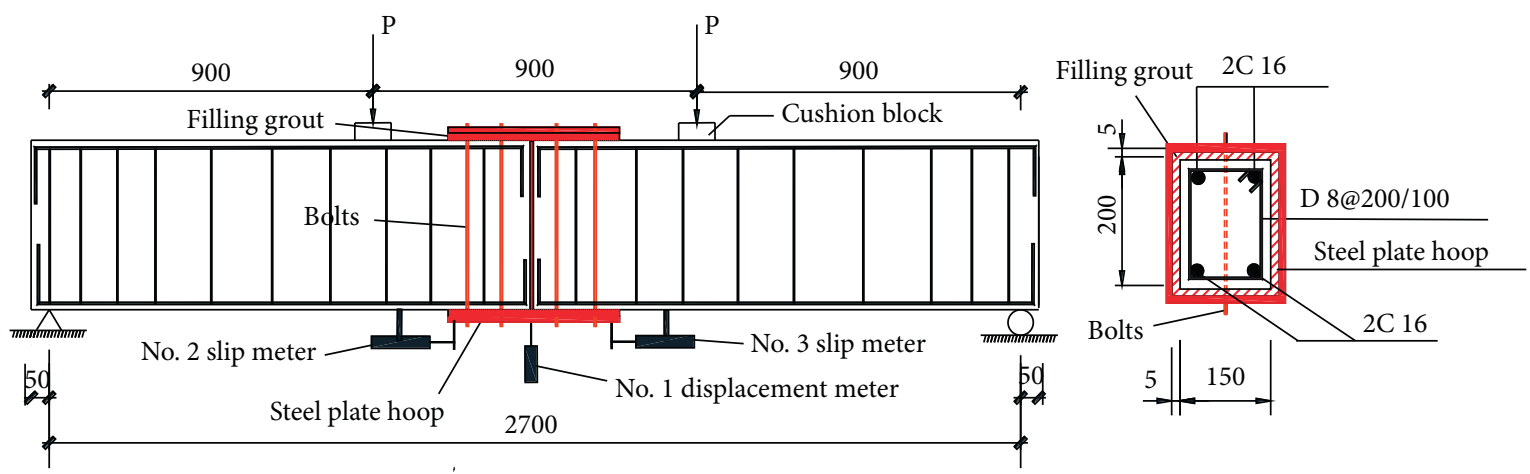

(b)
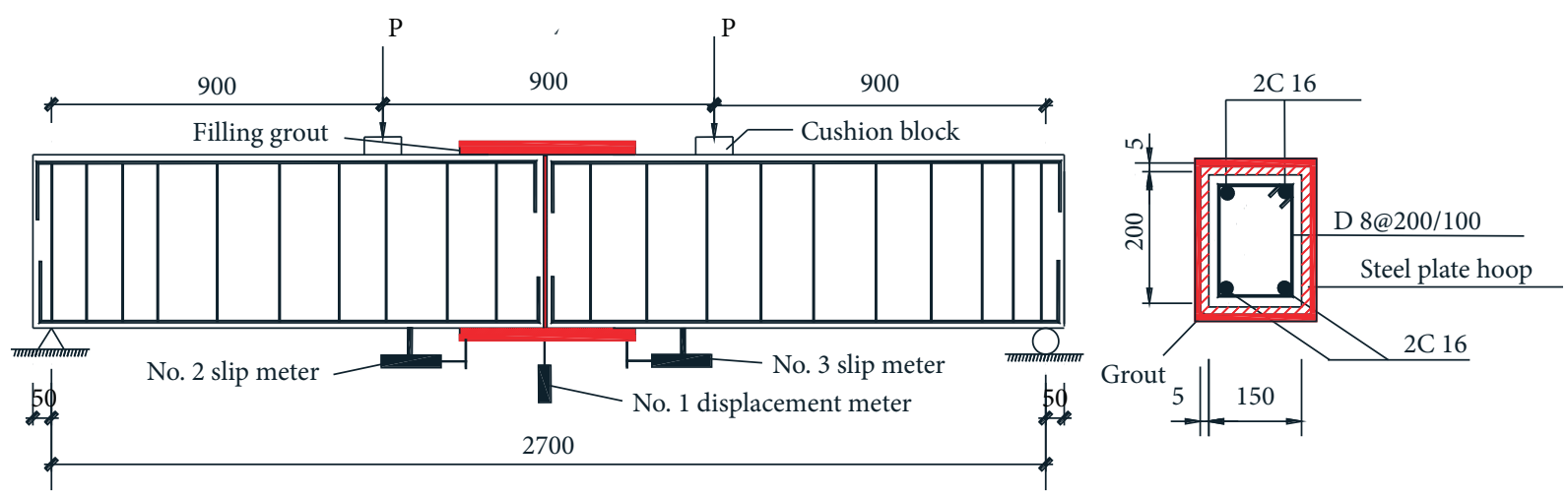

(c)

Figure 2: Specific size and structure of specimen. (a) Size and reinforcement of RCB-00, (b) size and reinforcement of PRCB-01 and PRCB02, and (c) size and reinforcement of PRCB-03-PRCB-06.

TABLe 1: Details of specimens.

\begin{tabular}{|c|c|c|c|c|c|}
\hline Specimen & $\begin{array}{l}\text { Cross-section of precast concrete } \\
\text { column }(\mathrm{mm} \times \mathrm{mm})\end{array}$ & $\begin{array}{c}\text { Actual measured thickness } \\
\text { of steel plate hoop (mm) }\end{array}$ & $\begin{array}{l}\text { Length of steel plate } \\
\text { hoop }(\mathrm{mm})\end{array}$ & Bolts & $\begin{array}{c}\text { Strength of } \\
\text { concrete }\end{array}$ \\
\hline RCB-00 & $150 \times 200$ & - & - & - & $\mathrm{C} 30$ \\
\hline PRCB-01 & $150 \times 200$ & 6.8 & 400 & $4 \mathrm{~d} 22 \mathrm{HRB} 400$ & $\mathrm{C} 30$ \\
\hline PRCB-02 & $150 \times 200$ & 6.8 & 500 & $4 \mathrm{~d} 22 \mathrm{HRB} 400$ & C30 \\
\hline PRCB-03 & $150 \times 200$ & 6.8 & 400 & - & $\mathrm{C} 30$ \\
\hline PRCB-04 & $150 \times 200$ & 6.8 & 500 & - & $\mathrm{C} 30$ \\
\hline PRCB-05 & $150 \times 200$ & 3.8 & 400 & - & $\mathrm{C} 30$ \\
\hline PRCB-06 & $150 \times 200$ & 3.8 & 500 & - & $\mathrm{C} 30$ \\
\hline
\end{tabular}




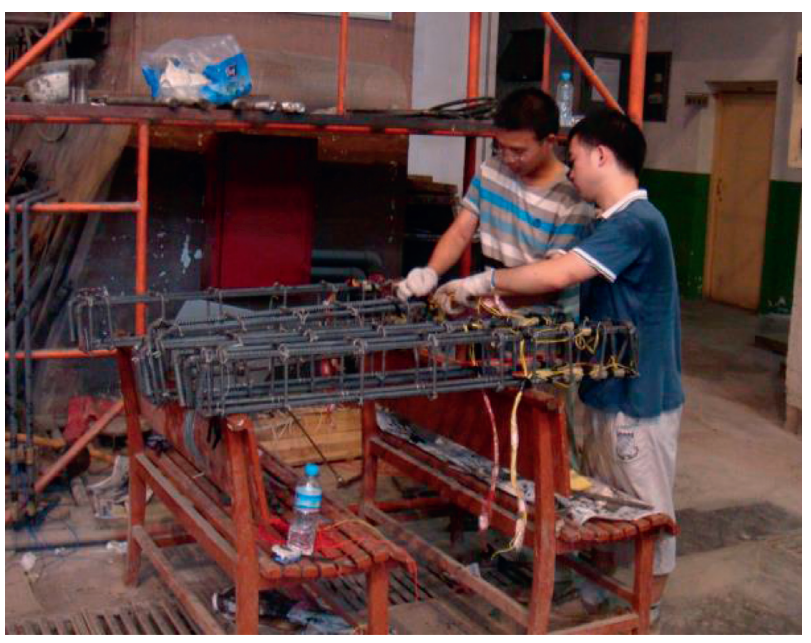

(a)

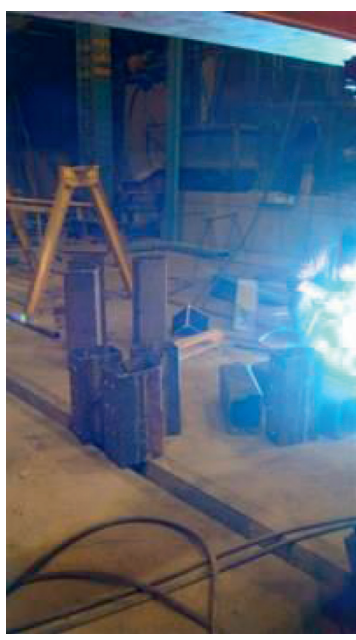

(b)

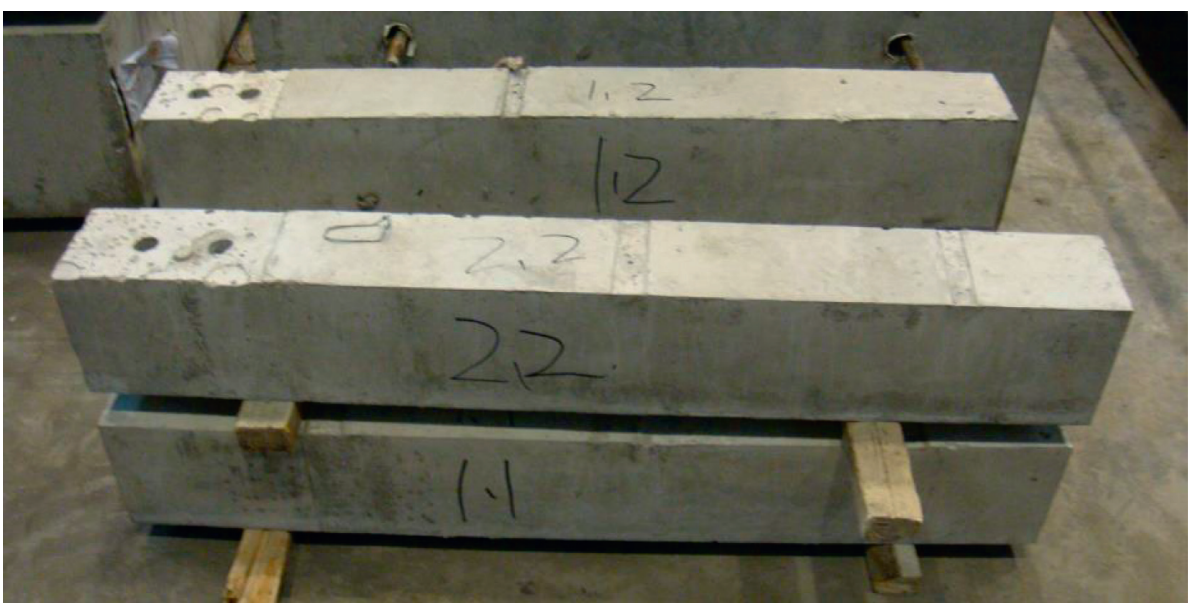

(c)

Figure 3: Specimen preparation. (a) Reinforcement skeleton of beam, (b) steel plate hoop, and (c) precast concrete components.

TABle 2: Mechanical properties of steel.

\begin{tabular}{lccccc}
\hline Type & $\begin{array}{c}\text { Steel } \\
\text { category }\end{array}$ & $\begin{array}{c}\text { Yield strength } f_{y} \\
(\mathrm{MPa})\end{array}$ & $\begin{array}{c}\text { Ultimate strength } \\
f_{u}(\mathrm{MPa})\end{array}$ & $\begin{array}{c}\text { Ultimate strength } \\
f_{v}(\mathrm{MPa})\end{array}$ & Yield strain $\varepsilon_{y}\left(10^{-6}\right)$ \\
\hline Steel plate hoop & Q235 & 290 & 400 & 180 & 1524 \\
Longitudinal reinforcement & d16 HRB400 & 450 & 610 & 320 & 2250 \\
$\begin{array}{l}\text { Bolt reinforcement } \\
\text { Stirrup }\end{array}$ & d22 HRB400 & d8 HRB400 & 520 & 720 & - \\
\hline
\end{tabular}

capacity of the specimen was lost due to the excessive deflection of the beam.

3.1.3. The Third Kind of Failure. When the loading value reaches $10 \mathrm{kN}$, the deflection of the beam begins to increase significantly, and the relative slip between the steel hoop and the concrete member also begins to increase obviously. When the load reaches $20 \mathrm{kN}$, cracks appear on the outside of the steel hoop, but the crack growth rate is slow. When the load reached $50 \mathrm{kN}$, the steel hoop was torn, and the bearing capacity of the beam lost its bearing capacity.

The deformation and failure of all specimens after test are shown in Figure 8.

\subsection{Analysis on Test Results}

3.2.1. Load-Deflection Curve. The deflection values of the tested beams were measured by No. 1 displacement meter, 


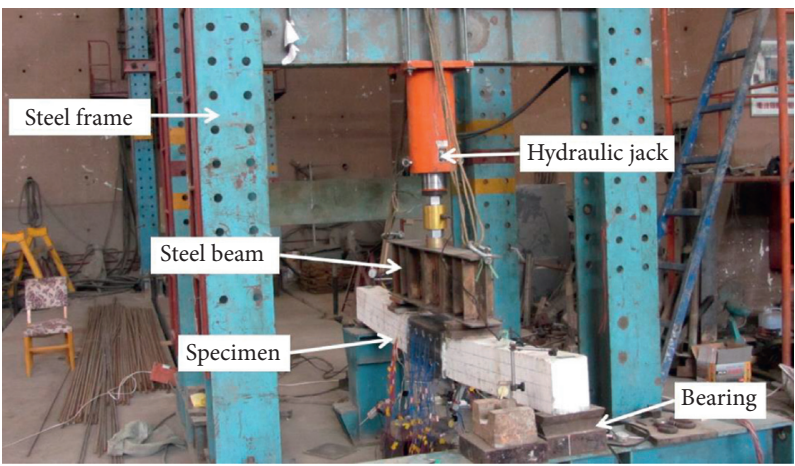

FIgure 4: Test loading device.

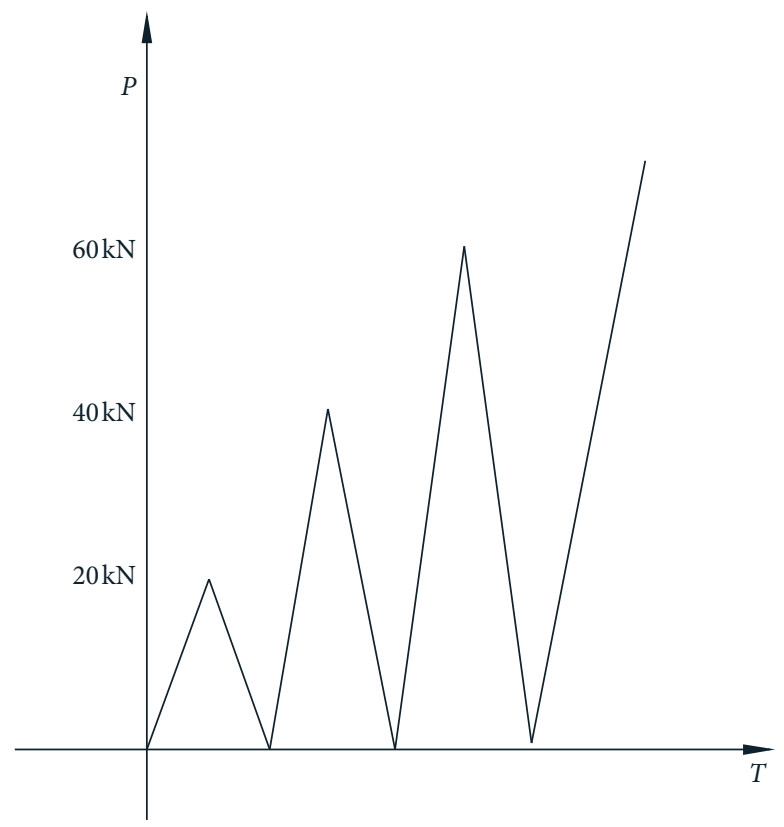

FIGURE 5: Loading history.

and the load deflection curves of seven beams were shown in Figure 9.

The curve shapes of Figures 9(a) and 9(c) are similar, but the ultimate deflection of PRCB-02 is slightly lower than that of RCB-00. Although the peak value and ultimate deflection of the curve in Figure 9(b) are similar to (a) and (c), the slope of the curve in the rising section is smaller, and the residual deflection after each unloading is larger. This shows that the new type of steel hoop with bolts has the same bearing capacity and deformation capacity as the integral casting.

Figures $9(\mathrm{~d})$ and 8 are similar in shape, but the peak load of both curves is less than (a). These two figures have obvious residual deflection, which indicates that the deflection recovery ability of the new type connection is small without bolts.

The shapes of (f) and (g) in Figure 9 are disorderly, and the peak load of the two curves is obviously smaller than other curves. In Figure 9(f), the sudden change after the peak load is caused by the tearing failure of steel hoop. Moreover, the abrupt decrease of residual deflection in Figure $9(\mathrm{~g})$ is caused by the recovery of relative slip between the steel hoop and the precast member.

Figure 10 shows the load deflection skeleton curves of seven test beams. The skeleton curves of RCB-00 and PRCB02 almost coincide. PRCB-01, PRCB-03, and PRCB-04 have a lower ultimate load but a similar shape. The ultimate load of PRCB-05 and PRCB-06 is the smallest, and the shape is quite different. It can be indicated that the thickness and length of the steel plate affect the bearing capacity and deformation of the specimens. Moreover, the bolts also play an important role in the new type connection.

3.2.2. Load-Slip Curve. The relative slip values are taken from the average values of the data measured by No. 2 and 3 slip meters in Figure 2. Figure 11 shows the load relative slip curve of six specimens with the new type connection. In Figure 11(a), PRCB-01 and PRCB-03 have the same thickness and length of the steel hoop, but the slip value of PRCB-01 is obviously smaller than PRCB-03. A similar case 


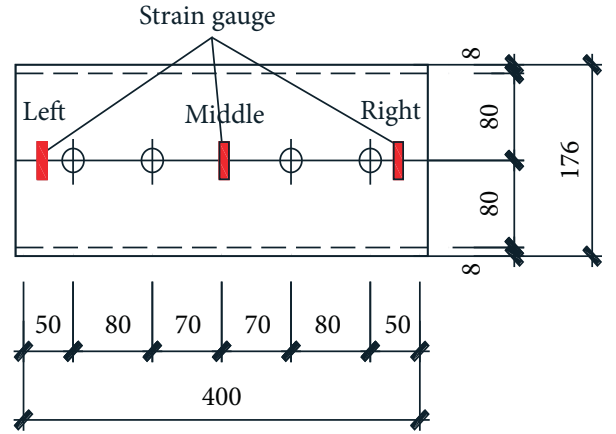

(a)

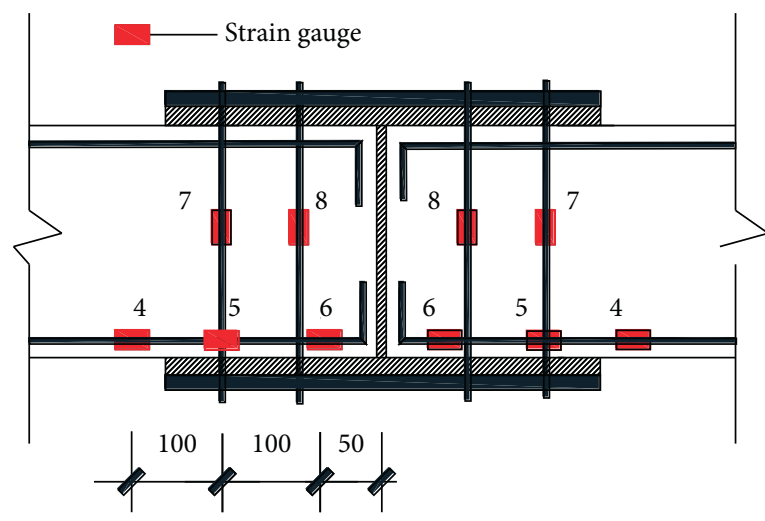

(c)
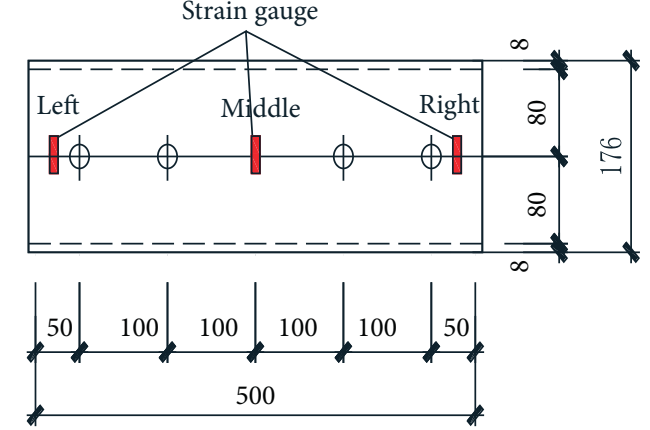

(b)

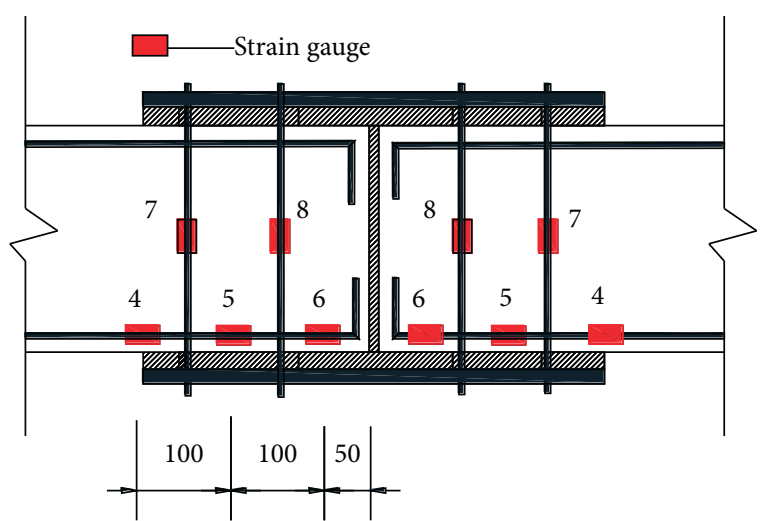

(d)

FIgURE 6: Strain gauge layout. (a) The position of bolts and gage in PRCB-01, (b) the position of bolts and gage in PRCB-02, (c) the position of bars gage in PRCB-01, and (d) the position of bars gage in PRCB-02.

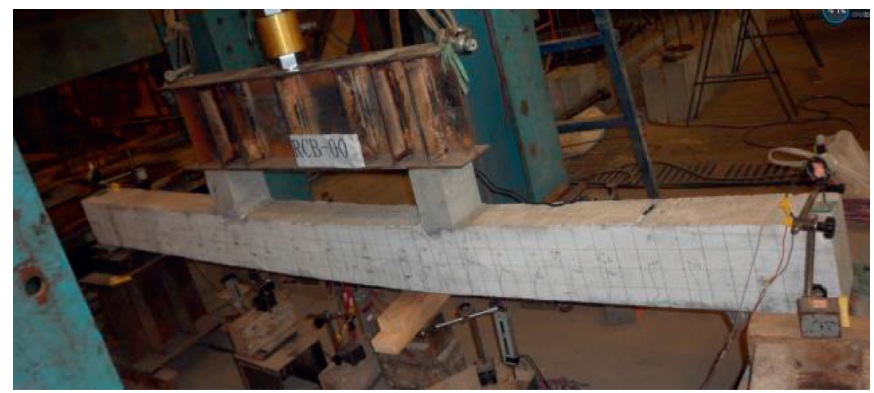

(a)

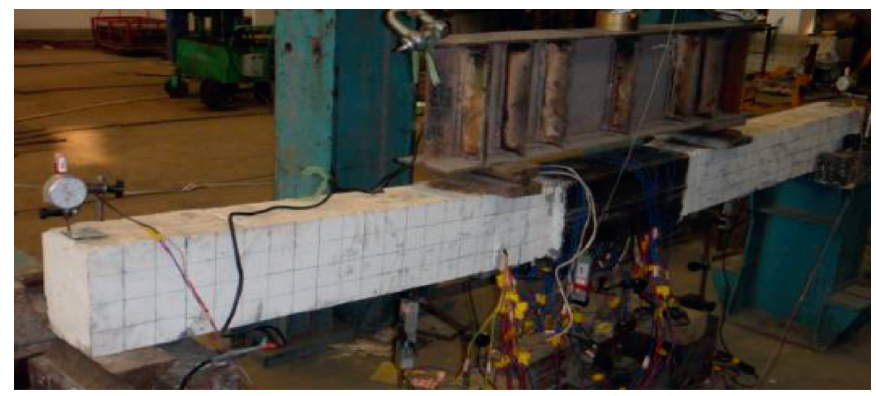

(c)

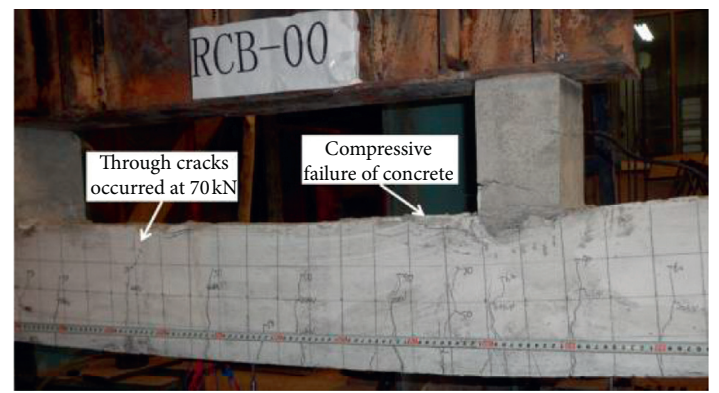

(b)

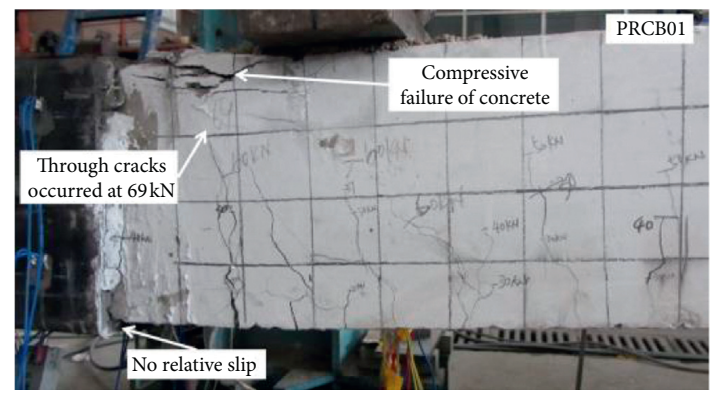

(d)

Figure 7: Continued. 


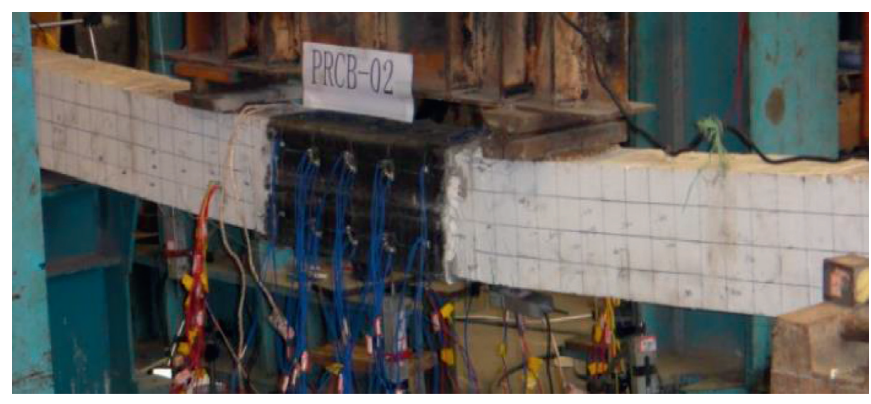

(e)

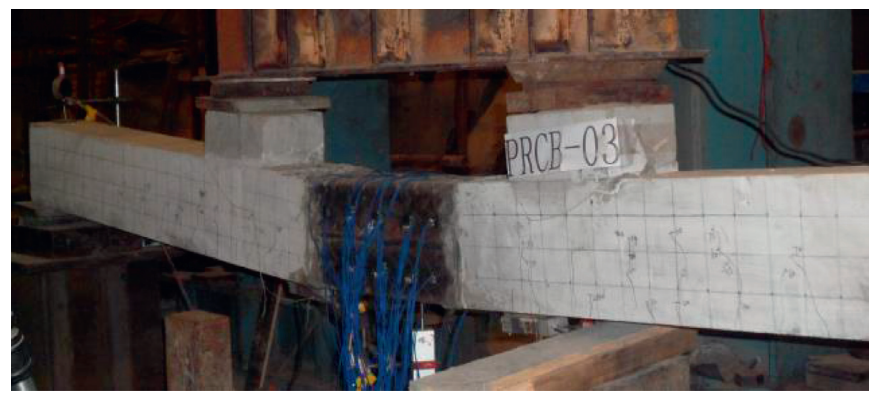

(g)

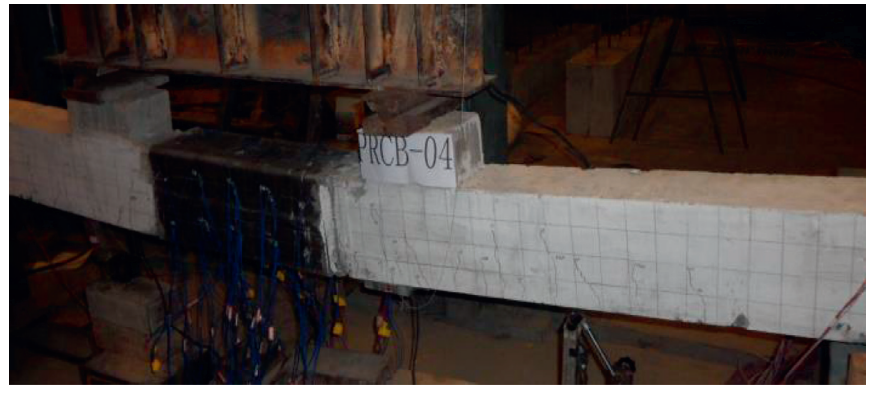

(i)

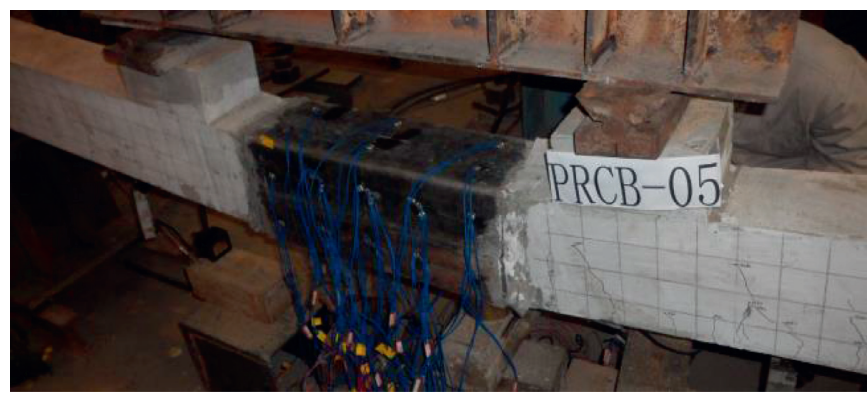

(k)

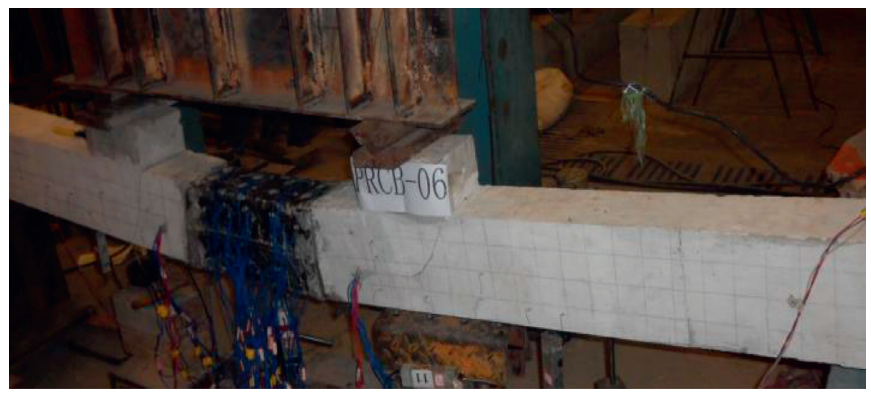

(m)

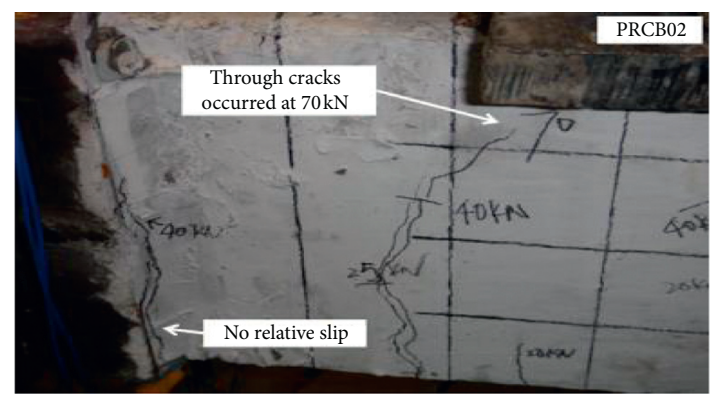

(f)

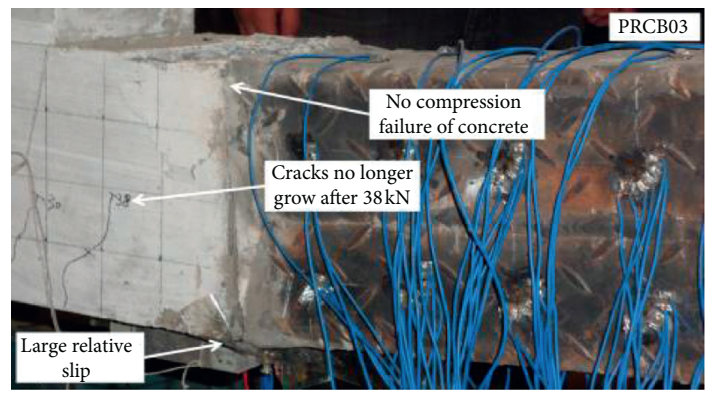

(h)

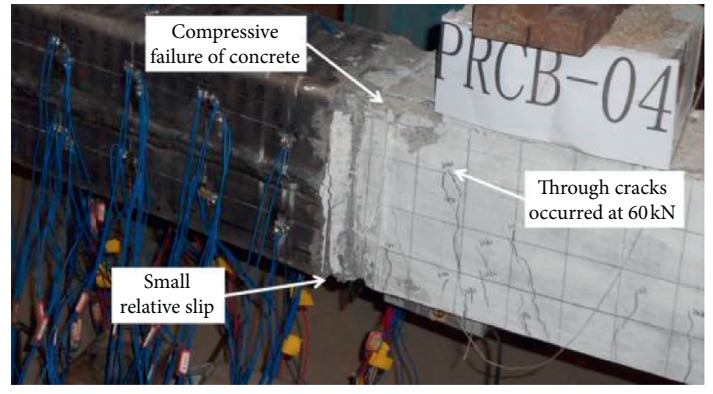

(j)

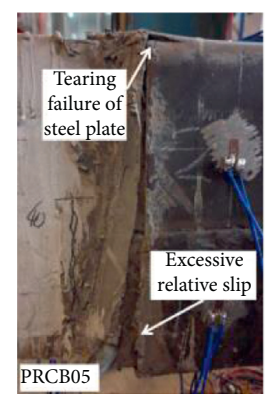

(l)

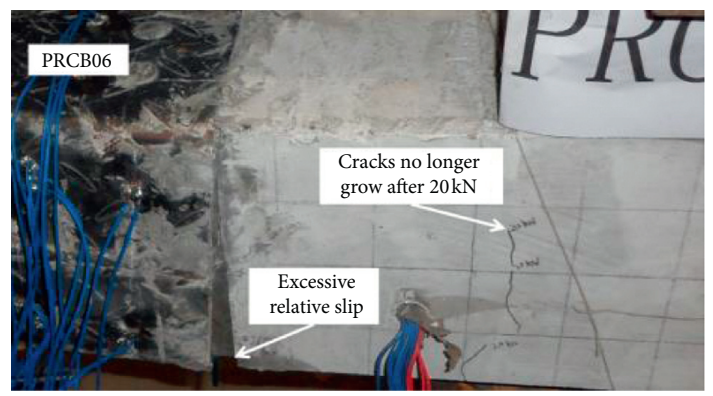

(n)

FIgURE 7: Loading diagram and failure modes. (a) PRCB-00 loading diagram, (b) PRCB-00 ultimate failure mode, (c) PRCB-01 loading diagram, (d) PRCB-01 ultimate failure mode, (e) PRCB-02 loading diagram, (f) PRCB-02 ultimate failure mode, (g) PRCB-03 loading diagram, (h) PRCB-03 ultimate failure mode, (i) PRCB-04 loading diagram, (j) PRCB-04 ultimate failure mode, (k) PRCB-05 loading diagram, (l) PRCB-05 ultimate failure mode, (m) PRCB-06 loading diagram, and (n) PRCB-06 ultimate failure mode. 


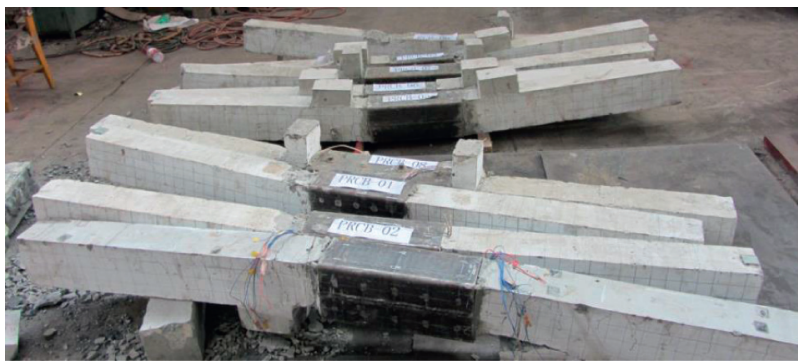

FIGURE 8: Specimen condition after test.

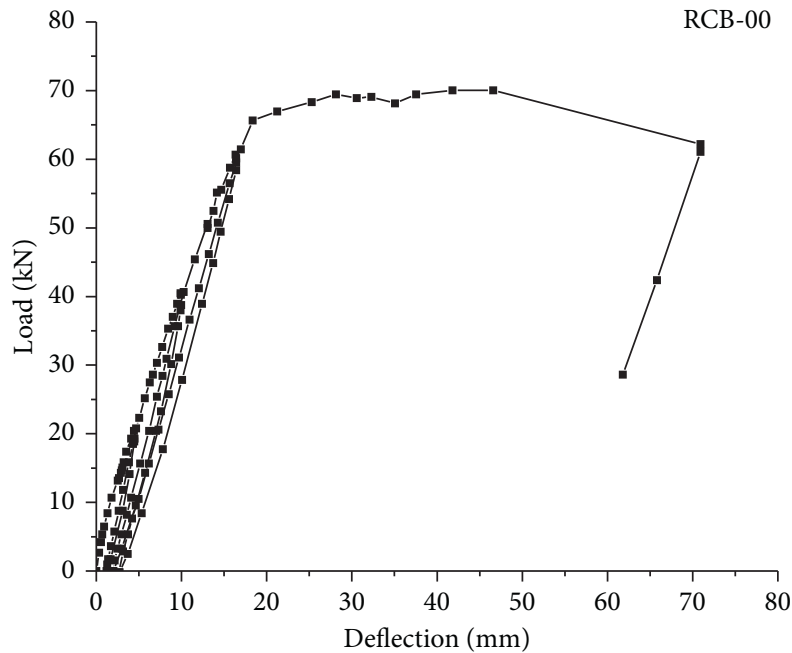

(a)

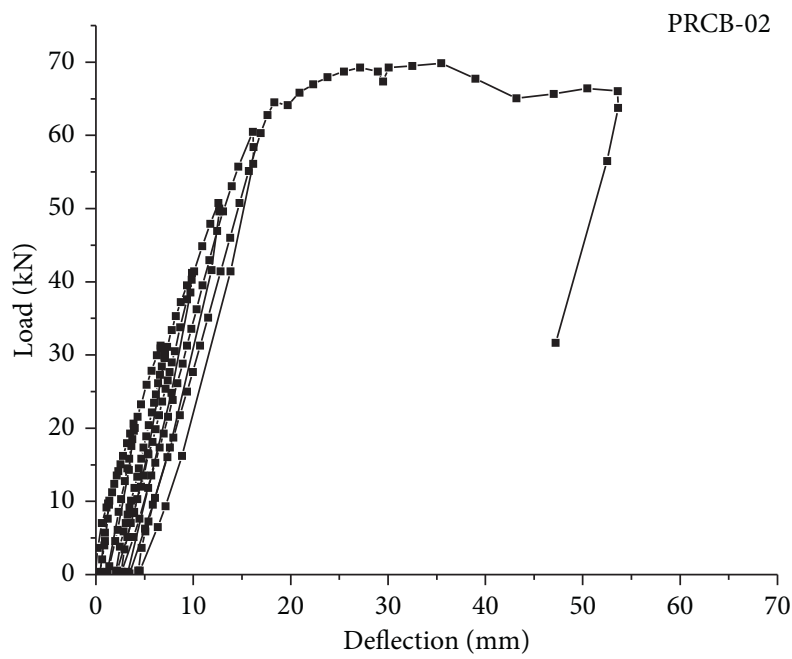

(c)

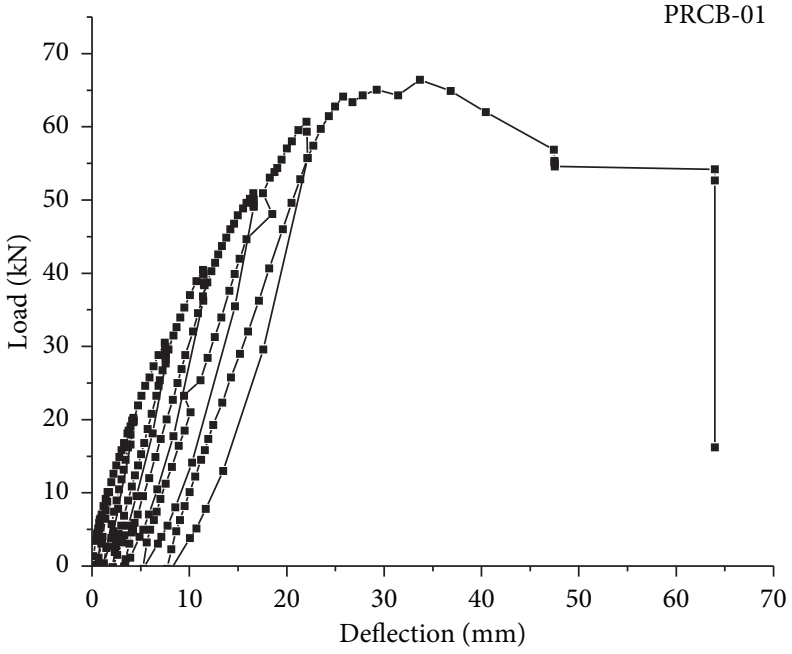

(b)

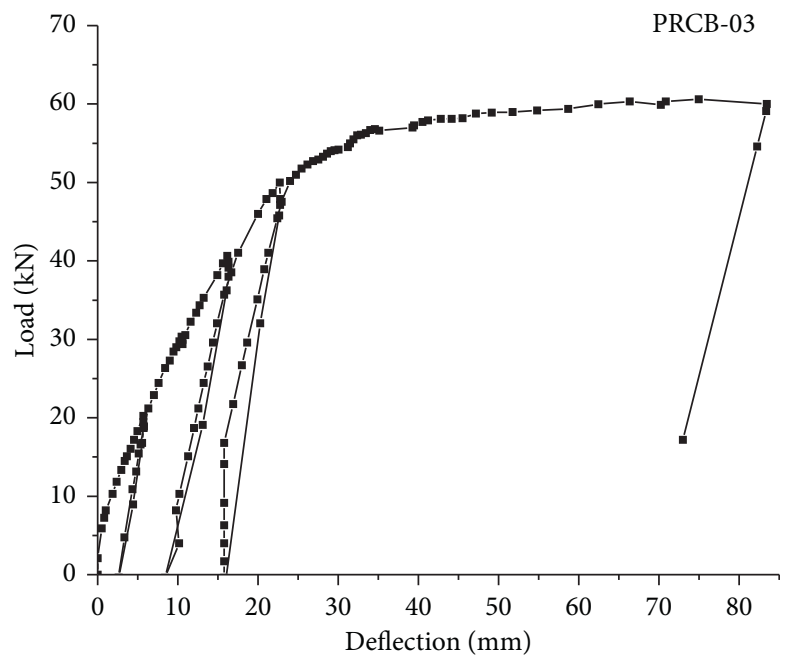

(d)

Figure 9: Continued. 


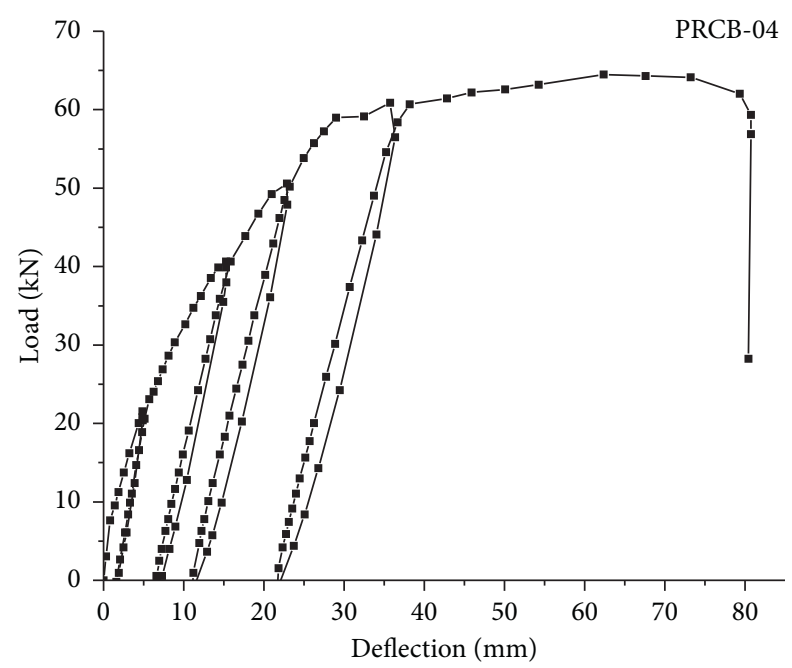

(e)

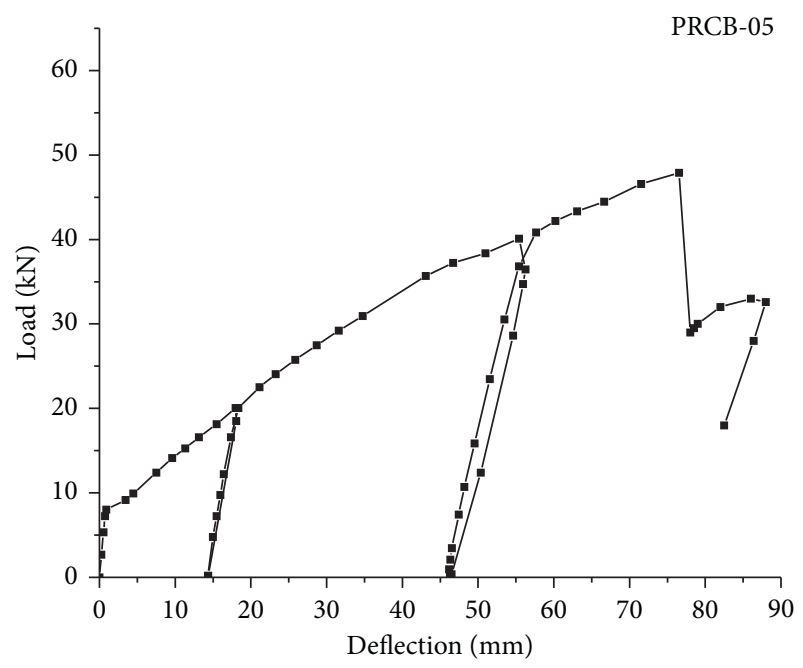

(f)

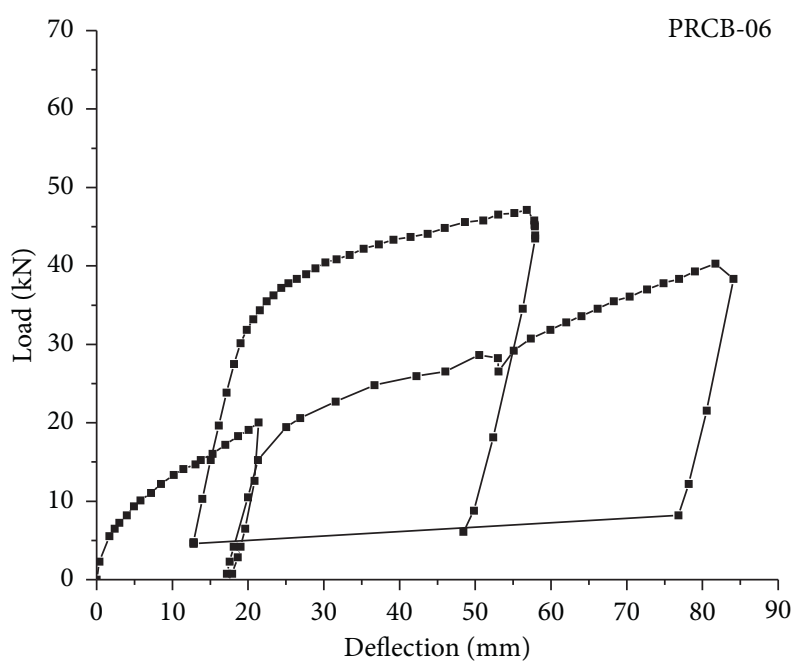

(g)

FIgURE 9: The curve of load-deflection.

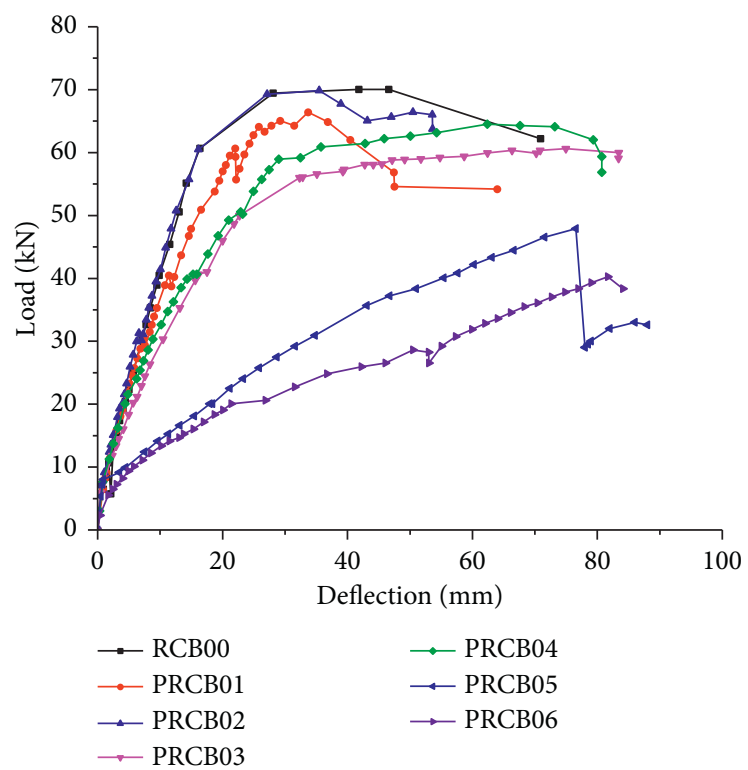

FIGURE 10: Load deflection curve. 
is also shown in Figure 11(b). These all indicate that the bolts effectively limit the relative slip between the steel hoop and precast member. In Figure 11(c), the load slip curves of PRCB-05 and PRCB-06 are obviously different. In the process of unloading, the relative slip increases suddenly, which indicates that when the thickness of steel hoop is small and cannot provide enough stiffness, this new type connection is not reliable.

According to the previously mentioned conclusion, the steel plate hoop connection with bolts is reliable, so the strain of PRCB-01 and PRCB-02 are specially analyzed.

3.2.3. Strain of Bolts. The strain values in Figure 12 are taken from the average strain values of bolts at position 7 . The maximum strain of the bolt is only about 700, which is far from reaching the yield strength of the bolts, indicating that the bolts did not bear a large tensile force during the test.

3.2.4. Strain of Steel Plate Hoops. Figures 13(a) and 13(b) show the load-strain skeleton curves of the top and bottom surface of the steel hoop in PRCB-01 and PRCB-02, respectively, and the curve shapes of the two test beams are similar. It can be seen from Figure 13 that there is almost no strain on the left and right sides of the steel hoop bottom during loading and unloading, while the strain of the steel plate hoop at the middle position increases with the increase of the load. This shows that the steel plate on the outside of the bolts bear almost no tensile force, while the steel plate on the inside of the bolts bear the main tensile force. The stress at the top of the steel plate hoop is different from that at the bottom, and the whole hoop bears the pressure, but compression strain in the middle increases faster than that in the left and right sides.

3.2.5. Load-Strain Curve of Longitudinal Reinforcement. Figure 14 shows the strain curve of longitudinal reinforcement in RCB-00, PRCB-01, and PRCB-02 at position 4, which is located outside the steel plate hoop as shown in Figure 6. The strain value of longitudinal reinforcement is the average value of all longitudinal reinforcement strains at the position 4 . The load-strain curves of the three specimens almost coincide, which indicates that the longitudinal bars in the precast concrete members have similar stress state outside the steel hoop. These show that the connection of steel hoop with bolts can effectively transfer the tensile force of longitudinal reinforcement.

Figures 15(a) and 15(b) are the load-strain curves of longitudinal bars in PRCB-01 and PRCB-02 at positions 4, 5, and 6 , respectively. The specific positions of No. 4, 5, and 6 are shown in Figure 6 . It can be seen from the figure that the tensile strain of the longitudinal bar at position 4 is the largest during loading and unloading, followed by position 5 , while the longitudinal bar at position 6 has almost no tensile strain. Considering the change of tensile strain at the bottom of the steel hoop, we can get that the tensile force of the longitudinal bar is transferred to the steel plate through the bolts.

\section{Bending Mechanism Analysis}

From the previously mentioned test results, the main factors affecting the bending capacity of the beam are the length and thickness of the steel hoop, the bolts configuration, and so on. The stress mechanism of the steel hoop with bolts connection mode and pure steel plate hoop connection mode is analyzed, respectively, to find out the action mechanism of each influencing factor.

4.1. Bending Capacity of Steel Hoop with Bolts. The pure bending section of PRCB-01 and PRCB-02 is isolated, and the stress situation is shown in Figure 16. Prefabricated components A and B are connected with steel plate hoop and bolt reinforcements. Under the bending moment, the relative movement trend is shown in Figure 17. In Figure 17, the cross-section 1-1 belongs to reinforced concrete, while the cross-section 2-2 belongs to concrete filled steel tube. Moreover, these two sections are typical weak sections under bending moment. Therefore, the flexural capacity of crosssection 1-1 can be calculated according to the code for design of concrete structures [14], and the bearing capacity of crosssection 2-2 can be calculated according to the technical specification for concrete filled rectangular steel tube structures [17]. The calculation formula of the flexural capacity at the two sections is as follows:

$$
\begin{aligned}
M_{u 1} & =\alpha_{1} f_{c} b x\left(h_{0}-\frac{x}{2}\right)+A_{s}^{\prime} \sigma_{y}^{\prime}\left(h_{0}-a_{s}^{\prime}\right), \\
\alpha_{1} f_{c} b x+f_{y}^{\prime} \sigma_{y}^{\prime} & =f_{y} A_{s},
\end{aligned}
$$

where $M_{u 1}$ the flexural capacity of section $1-1 ; \alpha_{1}$ is equivalent coefficient of concrete; $f_{c}$ is strength of concrete; $A_{s}^{\prime}$ is section area of longitudinal reinforcement in compression zone; $h_{0}$ is effective height of section; $\alpha_{s}^{\prime}$ is the distance from the resultant force point to the edge of the section.

$$
\begin{aligned}
M_{u 2} & =\left[0.5 A_{s}\left(h-2 t-d_{n}\right)+b t\left(t+d_{n}\right)\right] f_{y}, \\
d_{n} & =\frac{A_{s}-2 b t}{4 t+(b-2 t)\left(f_{c} / f_{y}\right)}
\end{aligned}
$$

where $M_{u 2}$ the flexural capacity of 2-2 section; $A_{s}$ is section area of steel plate hoop; $f_{y}$ is the tensile capacity of steel tube; $b$ is the length of rectangular steel pipe; $h$ is the width of rectangular steel pipe; $t$ is the thickness of steel pipe; $d_{n}$ is the height of concrete compression zone in steel pipe.

4.2. The Section Area of Bolts. According to the situation in Figure 17, we can separate the prefabricated member A and its bolts, and the stress situation of this part is shown in Figure 18. According to the test results in Figures 9 and 12, the bolts mainly resist the slip between the concrete member and the steel plate hoop, so the bolts mainly bear shear force and little tensile force. For the test beam without bolts reinforcement in Figure 9, the relative slip between the prefabricated member and the steel hoop is obvious and 


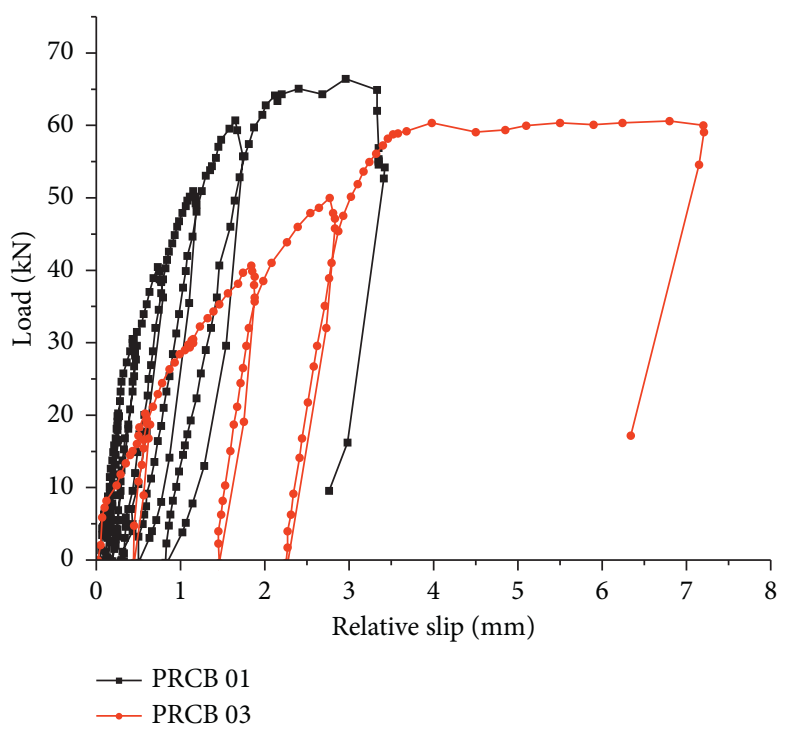

(a)

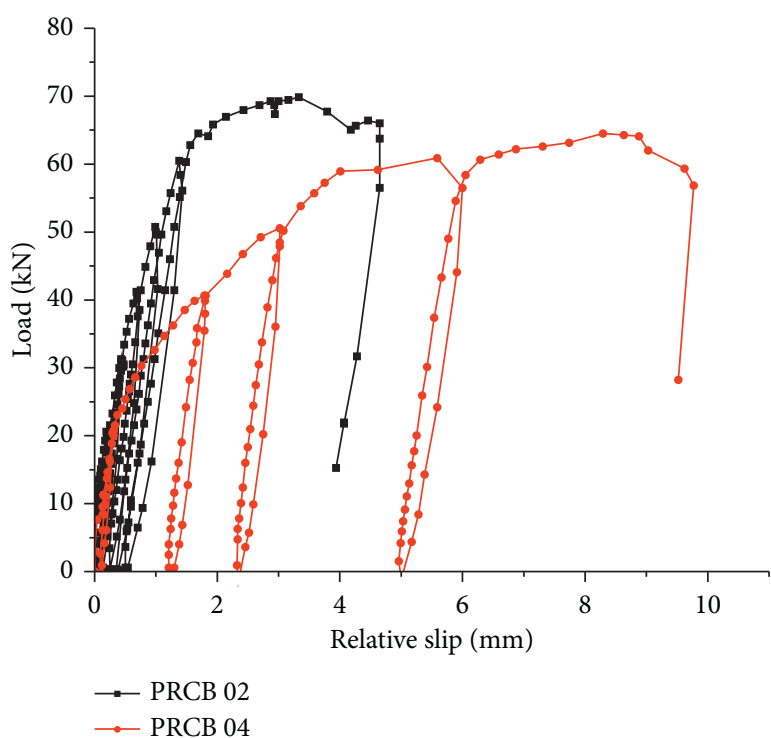

(b)

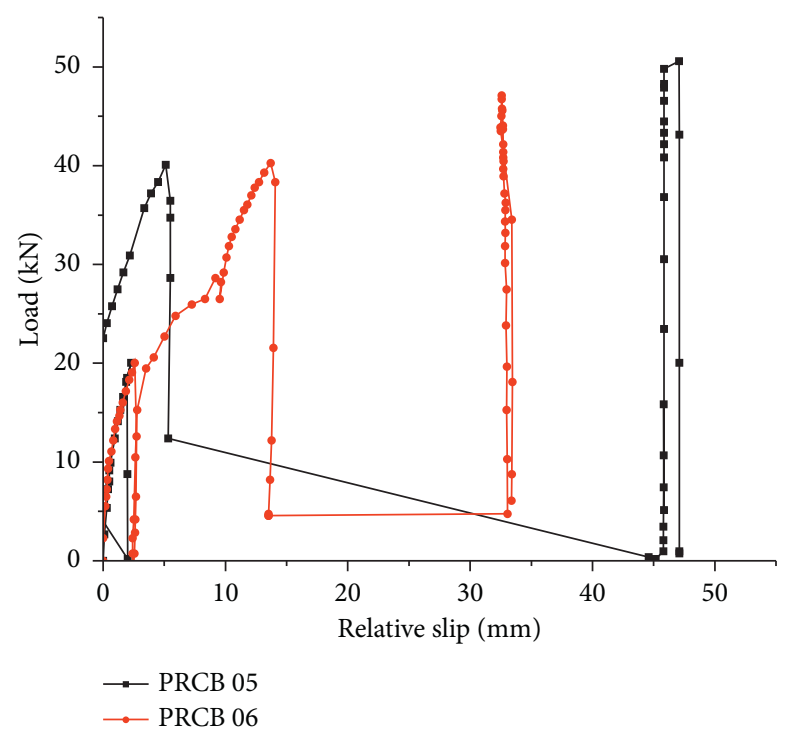

(c)

FIGURE 11: Load relative slip curve.

irrecoverable. Therefore, we can judge that the values of friction $\tau_{a}$ and $\tau_{b}$ between steel plate and concrete are small. We can ignore the frictions $\tau_{a}$ and $\tau_{b}$, which can also make the calculation of bolts' shear capacity more secure. According to the moment balance in Figure 18, we can obtain the following:

$$
f_{v} A_{s v} \cdot h_{0}^{\prime}+\left(\int_{0}^{b} \sigma_{c b} d s\right) \cdot l_{s}^{\prime}=M,
$$

where $f_{v}$ is shear strength of bolt reinforcements, $A_{s v}$ is section area of bolt reinforcement, $h_{0}^{\prime}$ is the distance of the resultant force in the horizontal direction, $\sigma_{c b}$ is compressive stress of the concrete member in the lower area, and $l_{s}^{\prime}$ is the distance of the resultant force in the vertical direction. The range of $h_{0}^{\prime}$ in formula (5) is easy to estimate, which is between $0.8 h$ and $h$, where $h$ is cross-section height. Considering the safety of design, $h_{0}^{\prime}$ can be taken as $0.8 h$. The formula for calculating the cross-sectional area of bolt reinforcements can be deduced as follows:

$$
A_{s v}=\frac{M-\left(\int_{0}^{b} \sigma_{c b} \mathrm{~d} s\right) \cdot l_{s}^{\prime}}{f_{v} \cdot 0.8 h} .
$$

4.3. The Length of Steel Plate Hoop. The length and thickness of the steel plate hoop need to analyze the stress of the pure steel hoop connection. So, the deformation of pure steel plate hoop connection is shown under the action of bending moment in Figure 19, and the stress condition of the precast concrete component $\mathrm{A}$ is shown in Figure 20. 


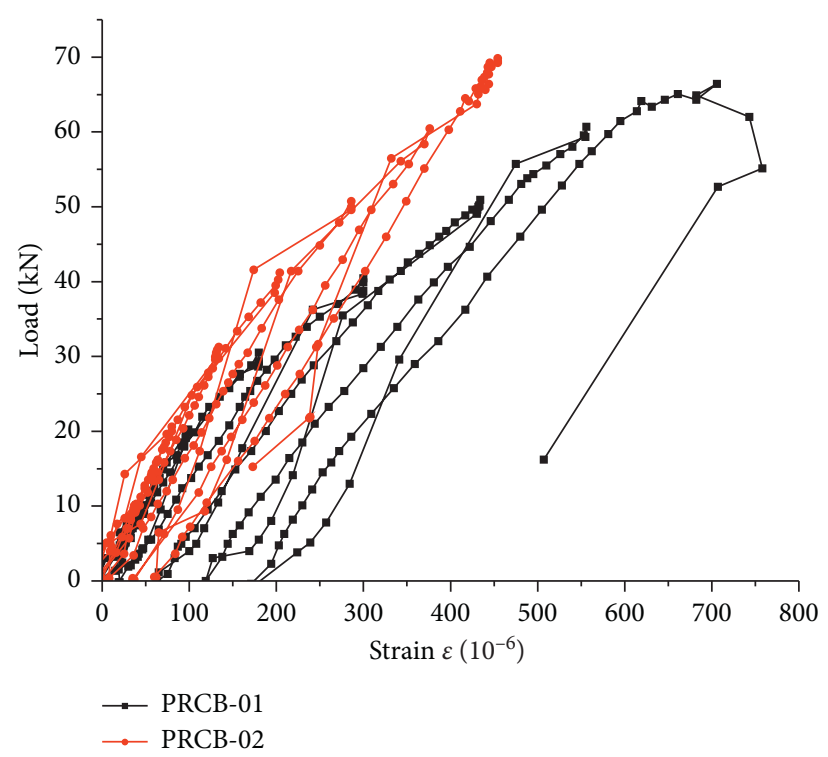

FIGURE 12: Strain curve of bolts at position 7.

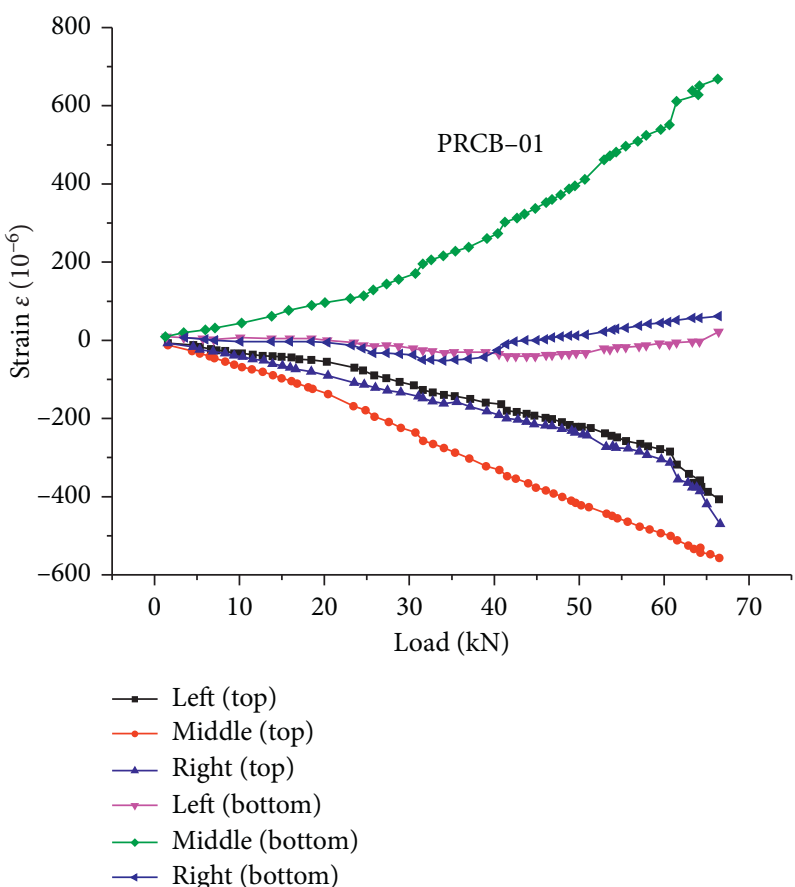

(a)

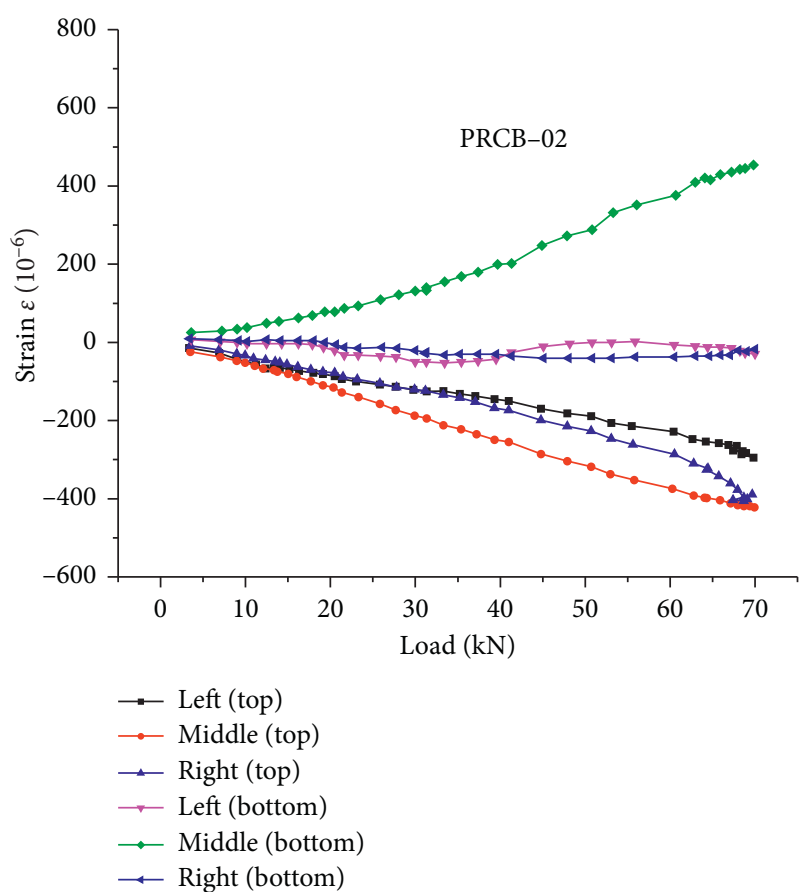

(b)

FIgURE 13: Load-strain curve of steel plate hoop bottom and top.

According to the mechanical equilibrium equation, the following three formulas can be obtained:

$$
\begin{aligned}
& \int_{0}^{l_{s} / z} \tau_{b} b \mathrm{~d} x=\int_{0}^{l_{s} / z} \tau_{a} b \mathrm{~d} x+\int_{0}^{h / z} \sigma_{c c} b \mathrm{~d} x, \\
& \int_{0}^{l_{s} / z} \sigma_{c b} b \mathrm{~d} x=\int_{0}^{l_{s} / z} \sigma_{c a} b \mathrm{~d} x,
\end{aligned}
$$

$$
M=\left(\int_{0}^{l_{s} / 2} \tau_{b} b \mathrm{~d} x\right) \cdot h_{0}^{\prime}+\left(\int_{0}^{l_{s} / 2} \sigma_{c b} b \mathrm{~d} x\right) \cdot l_{s}^{\prime},
$$

where $\tau_{a}$ and $\tau_{b}$ are the friction stress between concrete and steel plate, $\sigma_{c c}$ is the compressive stress between the precast member $\mathrm{A}$ and $\mathrm{B}, \sigma_{c a}$ and $\sigma_{c b}$ are the compressive stress between the precast member and the steel plate hoop, $h_{0}^{\prime}$ is the distance of the resultant force in the horizontal direction, 


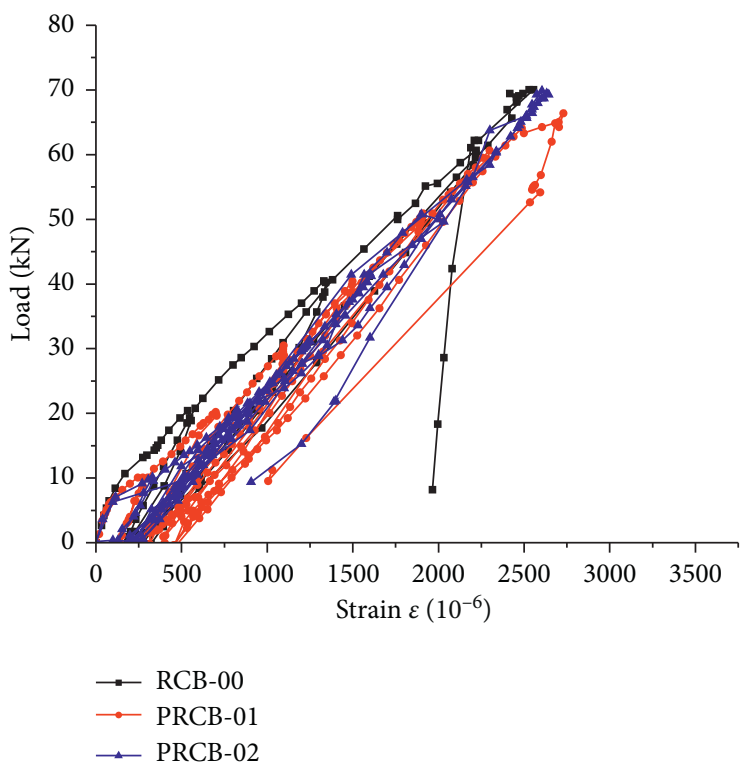

FIGURE 14: Strain curve of longitudinal reinforcement at position 4 in specimens.

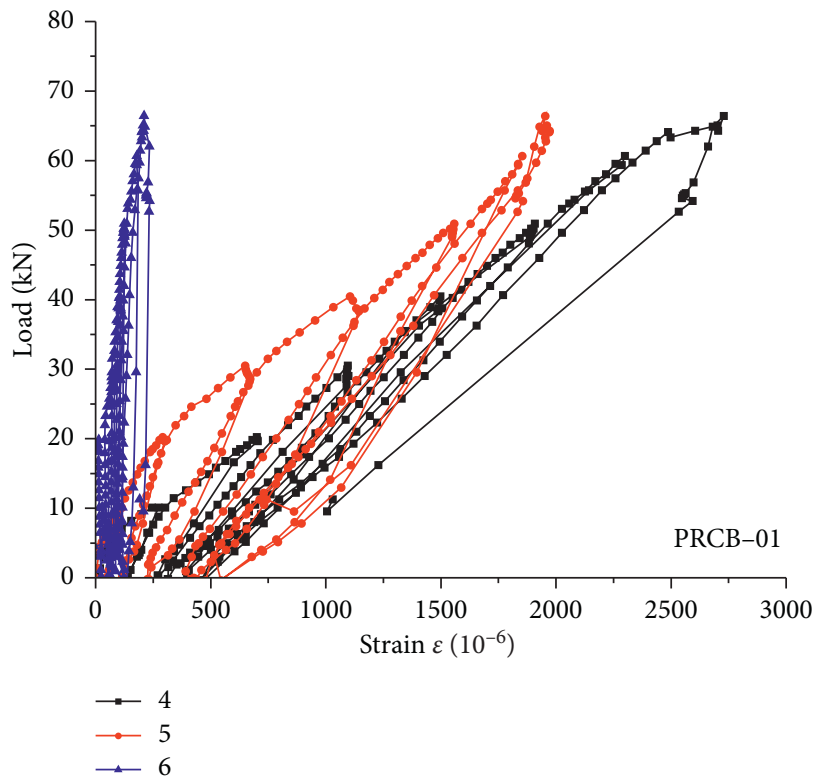

(a)

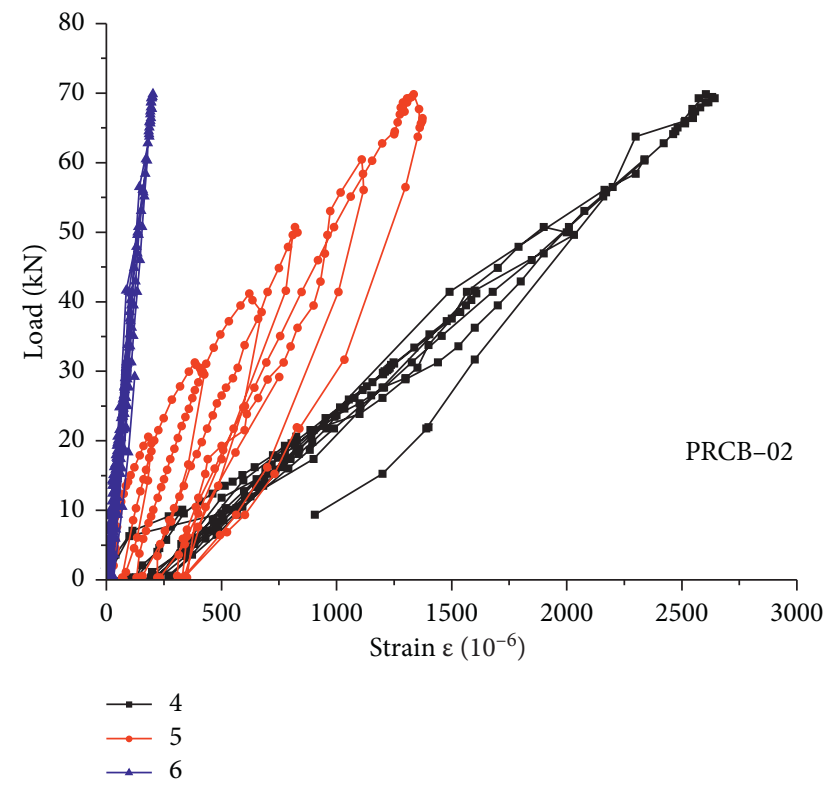

(b)

FIgURE 15: Strain curves of longitudinal bars in PRCB-01 and PRCB-02.

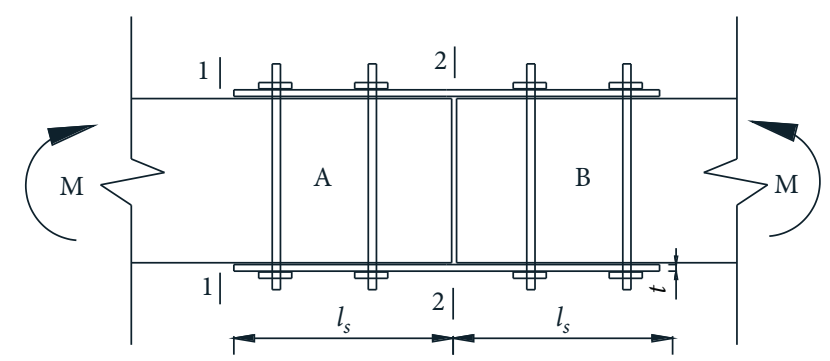

FIGURE 16: Pure bending section of the connection with steel plate hoop and bolts. and $l_{s}^{\prime}$ is the distance of resultant force couple in vertical direction.

In formula (7), $\tau_{b}$ will reach the limit state before $\tau_{a}$. According to the data provided in [18-20] and combined with the steel hoop and concrete materials in this test, the static friction coefficient between steel hoop and member is 0.2 . Therefore, the relation formula between $\tau_{b}$ and $\sigma_{c b}$ can be obtained $\tau_{b}=0.2 \sigma_{c b}$.

In formula (9), the range of $h_{0}^{\prime}$ is between 0.83 and 1 , which is deduced from the triangular distribution of compressive stress. From the safety point of view, $h_{0}^{\prime}$ can be taken 


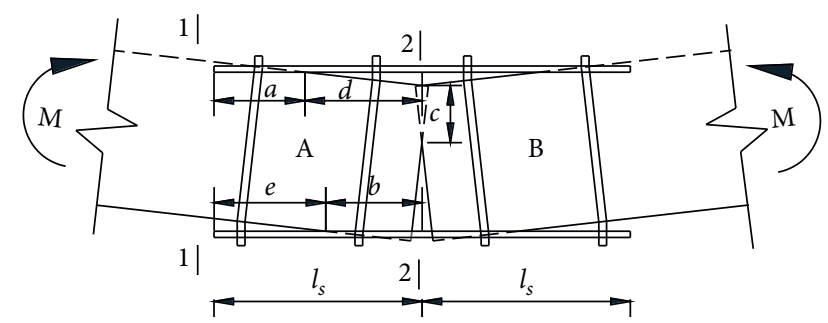

FIGURE 17: Deformation trend of isolator.

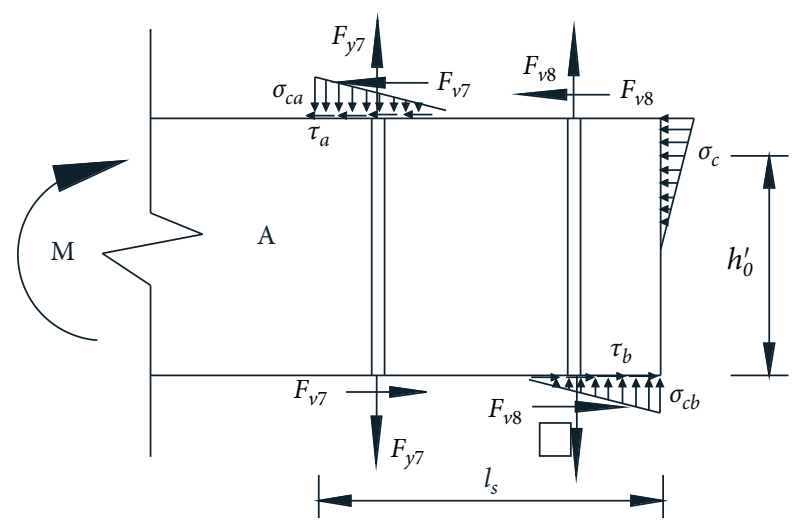

FIGURE 18: Stress condition of prefabricated component A.

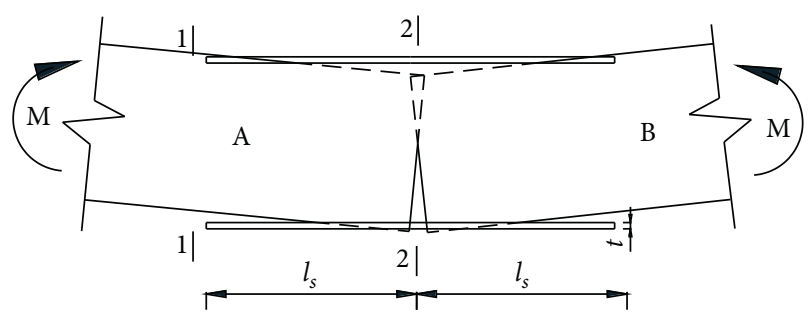

FIGURE 19: Deformation of steel plate hoop connection.

as the lower limit of 0.83 . When $\sigma_{c a}$ and $\sigma_{c b}$ reach the ultimate compressive stress, the value of $l_{s}^{\prime}$ can be obtained according to formula (10), where the constitutive relation of concrete is taken from code for design of concrete structures [14], and the calculated result is about $0.79 l_{s}$.

$$
l_{s}^{\prime}=\frac{\int_{0}^{l_{s} / 2} \sigma_{c}\left(\varepsilon_{c x}\right) b x \cdot \mathrm{d} x}{F_{a}}+\frac{\int_{0}^{l_{s} / 2} \sigma_{c}\left(\varepsilon_{c x}\right) b x \cdot \mathrm{d} x}{F_{b}} \approx 0.79 l_{s} .
$$

The conclusion of formula (10) can be obtained by substituting formula (11):

$$
M=0.319 f_{c} b l_{s}^{2}+0.08 f_{c} b l_{s} \cdot \frac{2}{3} h=(0.319+0.053 \omega) f_{c} b l_{s}^{2},
$$

where $\omega$ is $h / l_{s}$, and the value is near 1 . So, the $0.053 \omega$ is smaller than 0.319 , which can be ignored for convenience of calculation. So, we can get formula (12). When the length of steel hoop is more than twice $l_{s}$, this connection has enough bending capacity.

$$
l_{s}=\sqrt{\frac{M}{0.319 f_{c} b}}
$$

4.4. The Thickness of Steel Plate Hoop. To isolate the steel plate hoop in Figure 19, we can get its stress as shown in Figure 21. In Figure 21, the weakest link of steel hoop is the outermost upper corner. This part of steel hoop not only bears the maximum tension but also has the phenomenon of stress concentration [21]. Therefore, the upper steel plate is isolated from the corner, and the stress condition is shown in Figure 22. In order to ensure that the steel hoop does not tear during bending, the tensile force provided by the steel hoop is greater than that of the concrete. So, we can get the following formula (13).

$$
2 f_{y} t \mathrm{~d} s \geq f_{c} b \mathrm{~d} s
$$

where $f_{y}$ is the yield strength of steel hoop, $f_{c}$ is the compressive strength of concrete, $t$ is the thickness of steel hoop, $t$ is the width of the inner edge of the steel hoop, and $\mathrm{d} s$ is the length of microsegment in longitudinal direction. So, we can get formula (14) for the minimum thickness of $t$.

$$
t \geq \frac{f_{c} b}{f_{y}} .
$$

\section{Analysis of Theoretical Analysis and Experimental Results}

According to the previously mentioned stress analysis, the calculation results are shown in Table 3. $M_{u 1}$ is the flexural capacity of section 1-1, which is calculated by formula (1). $M_{u 2}$ is the flexural capacity of section 2-2, which is calculated by formula (3). $A_{s v}$ is a cross-sectional area of bolts, which is calculated by formula (6). $2 l_{s}$ is the minimum length of steel plate hoop, which is calculated by formula (12). $t$ is the minimum thickness of steel hoop, which is calculated by formula (14). The data in brackets are the actual thickness and length of steel plate hoop.

The loading value corresponding to $M_{u 1}$ can be calculated according to formula (15), which is consistent with the experimental results. However, the value of $M_{u 2}$ is larger than $M_{u 1}$, so there is no failure of section 2-2 in the test.

$$
P=6 \frac{M}{l}=6 \times \frac{28.36}{2.7}=63 \mathrm{kN} \cdot \mathrm{m} \text {. }
$$

The calculated value of bolts' cross-sectional area is $561 \mathrm{~mm}^{2}$, while the actual area is $760 \mathrm{~mm}^{2}$. Therefore, the shear failure of the bolts would not occur in this test, which is consistent with the test results.

The length of the steel hoop used in this test is greater than the calculation conclusion, so the concrete crushing failure in the steel hoop would not occur, which is basically consistent with the test results. It should be noted that the relative residual slip between the concrete member and steel hoop does not 


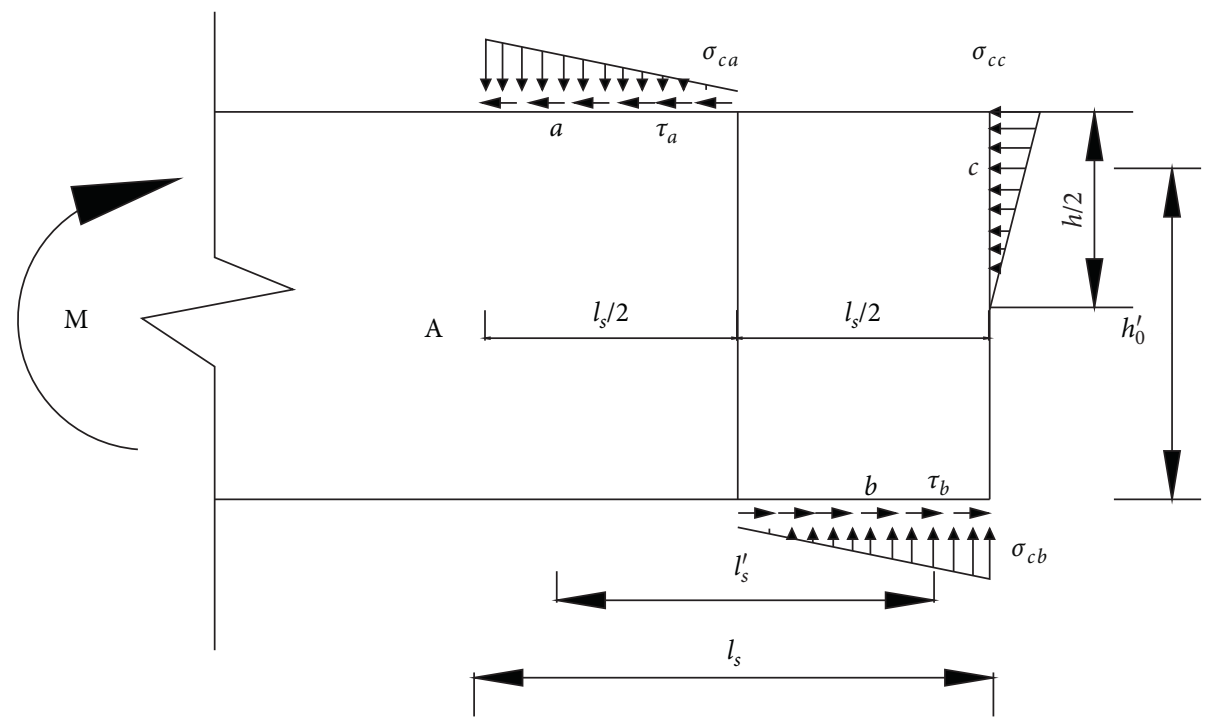

FIGURE 20: Stress condition of prefabricated component A.

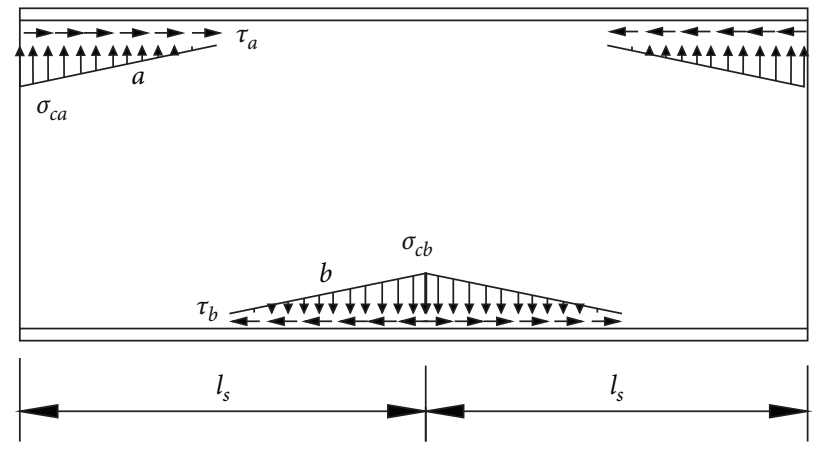

(a)

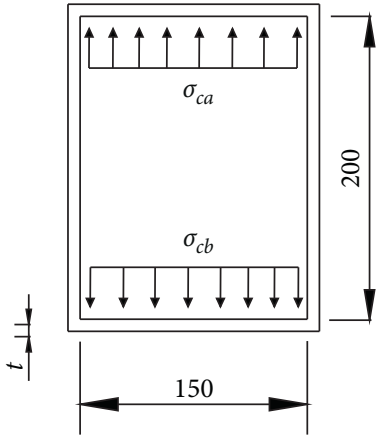

(b)

FIGURE 21: Stress condition of pure steel hoop.

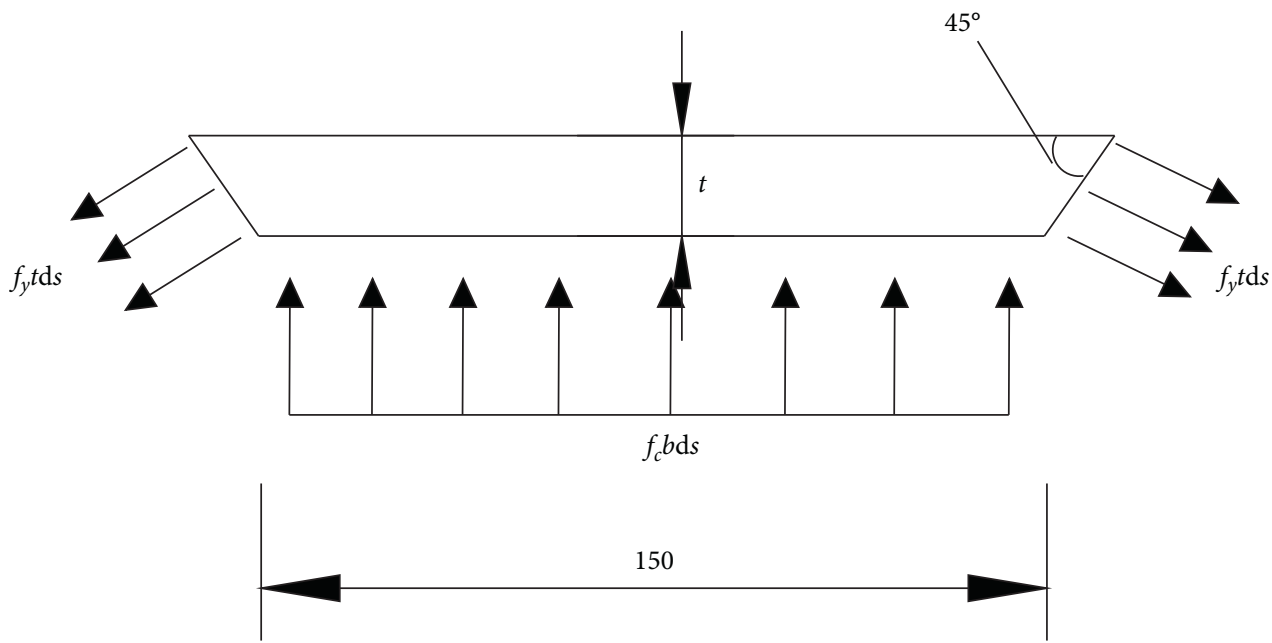

FIgURE 22: Stress condition of upper isolation body at steel hoop. 
TABLE 3: Theoretical calculation results.

\begin{tabular}{|c|c|c|c|c|c|}
\hline Specimen & $M_{u 1}(\mathrm{kN} \cdot \mathrm{m})$ & $M_{u 2}(\mathrm{kN} \cdot \mathrm{m})$ & $A_{s v}\left(\mathrm{~mm}^{2}\right)$ & $2 l_{s}(\mathrm{~mm})$ & $t(\mathrm{~mm})$ \\
\hline RCB-00 & 28.36 & - & - & - & - \\
\hline PRCB-01 & 28.36 & 100.89 & $561(760)$ & $266(400)$ & $5.85(6.8)$ \\
\hline PRCB-02 & 28.36 & 100.89 & $561(760)$ & $266(500)$ & $5.85(6.8)$ \\
\hline PRCB-03 & 28.36 & 100.89 & - & $266(400)$ & $5.85(6.8)$ \\
\hline PRCB-04 & 28.36 & 100.89 & - & $266(500)$ & $5.85(6.8)$ \\
\hline PRCB-05 & 28.36 & 76.57 & - & $266(400)$ & $5.30(3.8)$ \\
\hline PRCB-06 & 28.36 & 76.57 & - & $266(500)$ & $5.30(3.8)$ \\
\hline
\end{tabular}

disappear after each unloading in the steel hoop without bolts, which leads to a decrease in the actual length of the steel hoop.

The minimum thickness of steel plate hoop is calculated as $5.30 \mathrm{~mm}$, while the measured minimum thickness of steel plate is only $3.8 \mathrm{~mm}$, which is less than the minimum thickness of steel plate. Therefore, the tearing failure of steel plate occurs, which is consistent with the test results, as shown in Figure 7(l).

\section{Conclusion}

(1) The flexural failure mode, bearing capacity, and deflection deformation of one cast-in-place member, two bolt anchored steel braced joint members, and four pure steel braced joint members were tested under cyclic loading.

(2) According to the stress mechanism, the design formula of the new assembly connection mode is derived, such as the minimum length of steel plate hoop, minimum thickness $t$ of steel plate hoop, and minimum cross-section area of bolts. The rationality of the design formula is verified by comparing the test results with the calculation results.

(3) The experimental results and mechanical mechanism analysis prove that this new type of fabricated connection has a better bending performance than the cast-in-place members with the same crosssection and can meet the requirements of beam column assembly connection.

(4) The formula for calculating the minimum cross-sectional area of bolts proposed in this paper ignores factors such as concrete compressive stress and bond strength, and the calculation results are too conservative. Therefore, further experimental study is needed.

\section{Data Availability}

The data used to support the findings of this study are available from the corresponding author upon request.

\section{Conflicts of Interest}

The authors declare that they have no conflicts of interest.

\section{References}

[1] I. Holly and I. Abrahoim, "Connections and joints in precast concrete structures," Slovak Journal of Civil Engineering, vol. 28, no. 1, pp. 49-56, 2020.
[2] E. Akpinar, H. M. Atalay, and S. Ozden, "Performance of precast concrete structures in October 2011 Van earthquake, Turkey," Magazine of Concrete Research, vol. 66, no. 11, pp. 543-552, 2014.

[3] H. Richard and I. Jason, "Behaviour of tilt-up precast concrete buildings during the 2010/2011 Christchurch earthquakes," Structural Concrete, vol. 12, no. 4, pp. 234-240, 2011.

[4] D. Mitchell, R. H. Devall, M. Saatcioglu, R. Simpson, R. Tinawi, and R. Tremblay, "Damage to concrete structures due to the 1994 Northridge earthquake," Canadian Journal of Civil Engineering, vol. 22, no. 2, pp. 361-377, 1995.

[5] X. K. Huang, C. Y. Tian, M. L. Wan, and R. Li, "Researches and applications of precast concrete structures in China," China Building Science, vol. 34, no. 9, pp. 53-58, 2018.

[6] Q. Luo and W. Yun, "Experimental study of tenon connection for precast monolithic R. C. frame column," Industrial Construction, vol. 38, no. 10, pp. 48-49, 2008.

[7] T. Nerio and M. Fabio, "Grouted sleeve connections used in precast reinforced concrete construction- experimental investigation of a column-to-column joint," Engineering Structures, vol. 127, pp. 784-803, 2016.

[8] R. Li, Y. M. Zheng, and Y. Zhao, "Experimental research on seismic columns with $5001 \mathrm{VIPa}$ reinforcements splicing performance of precast concrete by grout-filled coupling sleeves," Journal of Building Structures, vol. 37, no. 5, pp. 255-263, 2016.

[9] M. Wei and X. Fang, "Tests on behavior of precast columns with reinforcements spliced," Journal of Jiamusi University (Natural Science Edition), vol. 31, no. 3, pp. 352-361, 2013.

[10] W. Yan, W. Wang, and S. Chen, "Experimental study of the seismic behavior of precast concrete layered slab and beam to column exterior joints," China Civil Engineering Journal, vol. 43, no. 12, pp. 56-61, 2010.

[11] J. Wang, J. Zhao, and Z. Hu, "Review and thinking on development of building industrialization in China," China Civil Engineering Journal, vol. 49, no. 5, 2016.

[12] P. Gao, Y. Deng, A. Li, and F. Lu, "Review on seismic performance of connection joints of precast concrete frame structures GAO Peinan,” Industrial Construction, vol. 32021, in Chinese.

[13] Y. Chen, "Common quality problems and preventive measures in precast concrete building construction," Technology and Market, vol. 26, no. 5, pp. 197-199, 2019.

[14] B. Li and Y. Wen, "Study on mechanical properties of concrete filled rectangular steel tube beams," Building Structure, vol. 40, no. 6, pp. 51-52, 2006.

[15] GB/T50010-2010, Code for Design of Concrete Structures, 2010.

[16] GB/T50081-2019, Standard for Test Method of Mechanical Properties on Ordinary Concrete, 2019. 
[17] CECS 43:92(1992), Design Specification for Joints and Connections of Precast Monolithic Reinforced Concrete Frames, 1992.

[18] C. Petrus, H. Abdul Hamid, A. Ibrahim, and J. D. Nyuin, "Bond strength in concrete filled built-up steel tube columns with tab stiffeners," Canadian Journal of Civil Engineering, vol. 38, no. 6, pp. 627-637, 2011.

[19] X. L. Kang, H. T. Zhao, J. Y. Xue, and Z. Chen, "Summarized review of the bond slip problems of concrete filled steel tubes," Journal of Xi'an University of Architecture and Technology, vol. 38, no. 3, pp. 321-326, 2006.

[20] L. Xue and S. Cai, "Bond strength at the interface of concretefilled steel tube columns," Buildingence, vol. 3, no. 4, pp. 19-23, 1996.

[21] GB 50017-2017, Code for Design of Steel Structure, 2017. 